\title{
Designing an Electronic Platform for the Distribution and Managing Undergraduate Projects
}

\author{
Osama O. Mohammed \\ osama.csp76@student.uomosul.edu.iq
}

\author{
Shayma M. Mohi-Aldeen \\ shaymamustafa@uomosul.edu.iq
}

\section{Department of Computer Science \\ College of Computer Science and Mathematics \\ University of Mosul, Mosul, Iraq}

Received on: $25 / 01 / 2021$

Accepted on: 07/02/2021

\begin{abstract}
Our study in this research came as a proposal for an electronic platform to manage projects that graduate the fourth stage through which all tasks were transferred from the traditional system to an electronic system. As the system collects project proposals by the teachers and follows up the process of selecting them by the students, then managing the discussion process and sending the evaluation electronically by the members of the discussion committees and by connecting to the internal network (Router) via mobile or computer to the main database so that the system administrator prints the results The evaluation is processed electronically and submitted to the examination committee. The system was developed structurally according to the principle of the server and the client, and the wireless network was used to connect the system devices to transfer information between the server and the client. The system provided a protection method for system information and a way for users to enter, relying on efficient investigation methods to ensure safe access to all system interfaces. The system was tested on real information for the Computer Science Department, and the system showed its efficiency in achieving the required goals, completing the tasks, and issuing results accurately, quickly and without errors. Programming languages used in the design ( $\mathrm{C}$ \# for design interfaces + SQL Server for distributed database + PHP for web pages)
\end{abstract}

Keywords: Distributed Systems, Client|Server, Database, Computer Science Department-University of Mosul.

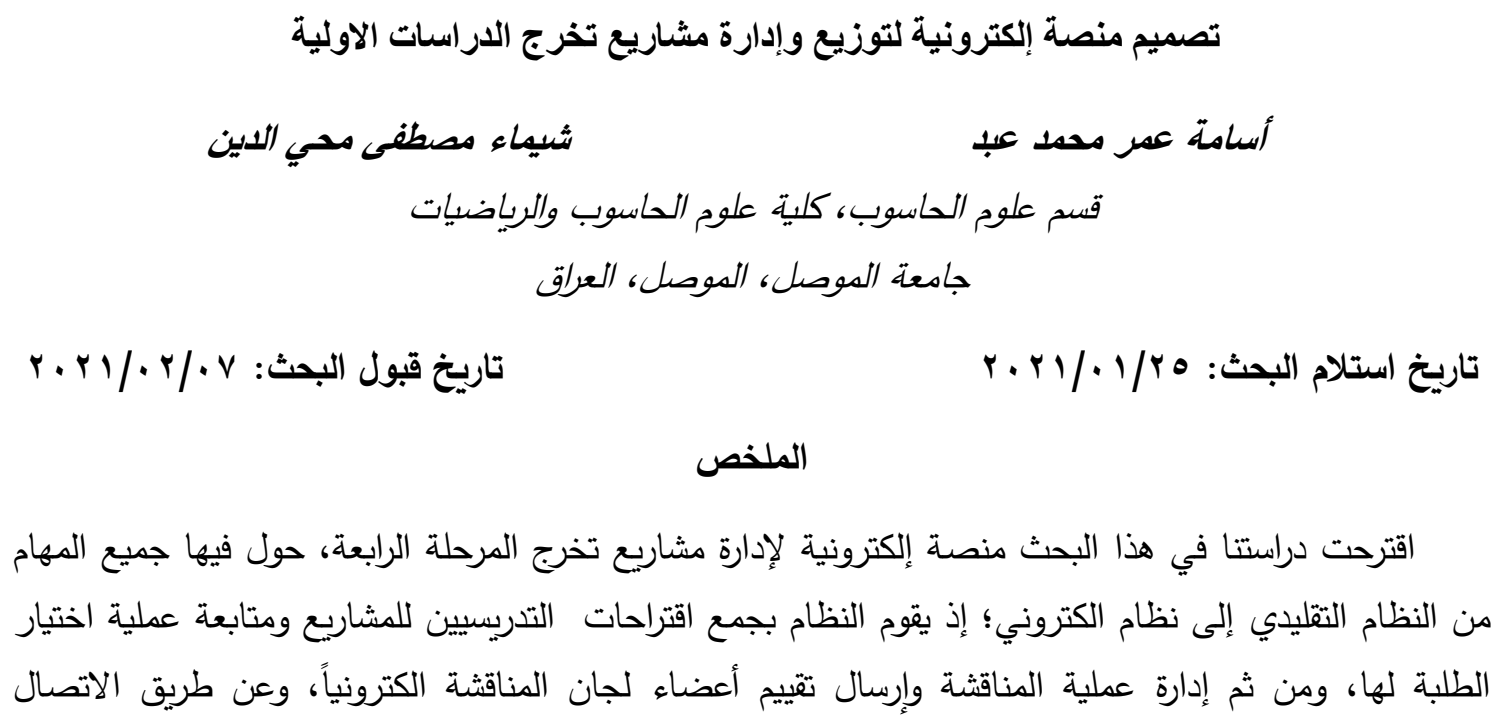


بالشبكة الداخلية Local Area Network(LAN) عن طريق الموبايل أو الكمبيوتر إلى قاعدة البيانات الرئيسة ليقوم مسؤول النظام بطباعة نتائج التقييم بعد معالجتها الكترونياً وتسليمها إلى اللجنة الامتحانية؛ طور النظام هيكلياً وفق مبدأ الخادم والزبون واستعملت الثبكة اللاسلكية في ربط أجهزة النظام لنقل المعلومات بين الخادم والربون (Clien-Server) (النظام طريقة حماية لمعلومات النظام وطريقة دخول المستخدمين بالاعتماد على طرائق تحقيق كفوهة لضمان الوصول الآمن لجميع واجهات النظام، اختبر النظام على معلومات حقيقية لقسم علوم

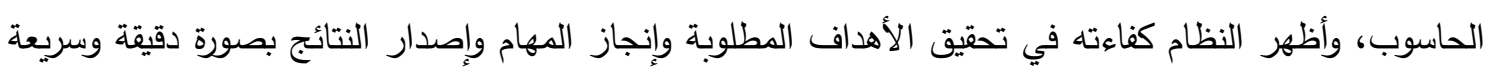
وبدون أخطاء، واللغات البرمجية المستخدمة في التصميم (C\# لتصميم الواجهات + SQL Server لقاعدة البيانات

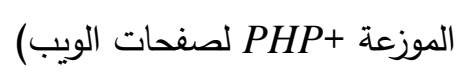

الكلمات المفتاحية: الأنظمة الموزعة، الخادم / الزبون، قواعد البيانات، قسم علوم الحاسوب-جامعة الموصل.

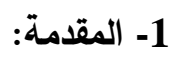

إن الاستعمال المتزايد والمتسارع للتكنولوجيا ودخولها مجالات الحياة كافة يُحتِ على الجميع مواكبة هذا

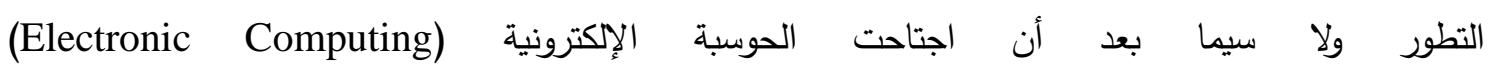
والاتصالات(Communications) كل الأنظمة التقليدية وعمدت إلى صياغتها بصيغة تقانة حديثة تلبي المتطلبات المنشودة بصورة سريعة وكفوهة [1]. وبذلك دأبت الكثير من المؤسسات التعليمية والتجارية إلى استخدام الأنظمة الحاسوبية في خزن بياناتها ومعالجتها بالطرائق التقانية الحديثة] [2]. ونظراً لما تقدمه هذه الأنظمة من كفاءة ودقة في تذليل صعوبات العمل، فقد ارتأت معظم المؤسسات والدوائر

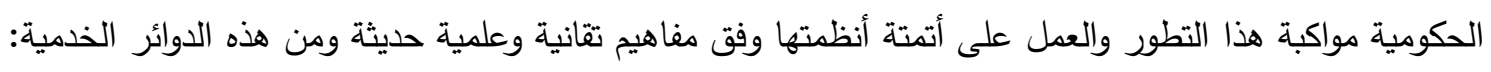

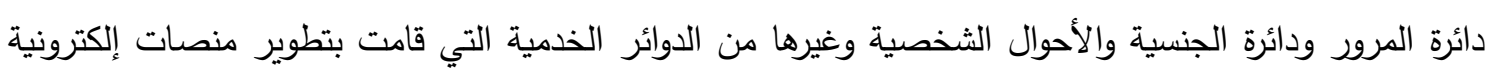
عملت على تسهيل وتذليل الكثير من المعوقات المصاحبة للأنظمة التقليدية من أجل تقديم خدمات ميسرة وسريعة الترائرة للمواطن. إن استخدام مفهوم الأنظمة الموزعة في تطوير الأنظمة التقليدية أسهم في زيادة أداء تلك الأنظمة [3][4].

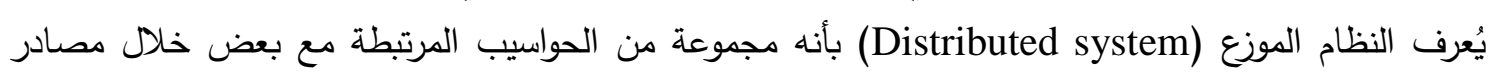

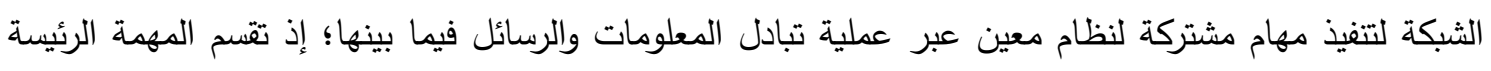
إلى عدد من المهام الجزئية لتوزع على عدد من الحواسيب ومن ثم إعادة جمعها في الحاسوب الرئيس وإظهار

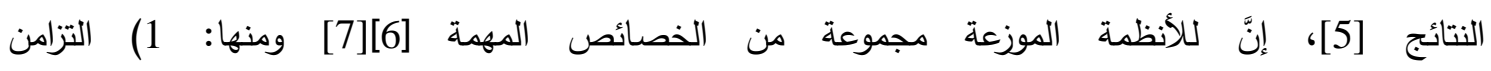
( Synchronization)

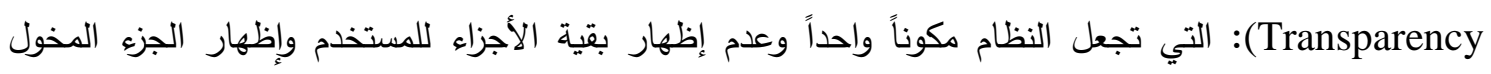
بالدخول إليه فقط. 3) الاعتمادية (Reliability): وهي أن يعمل النظام في كل الأوقات وبدون إخفاقات. 4 (أنسات

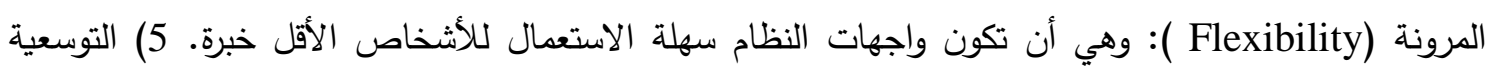

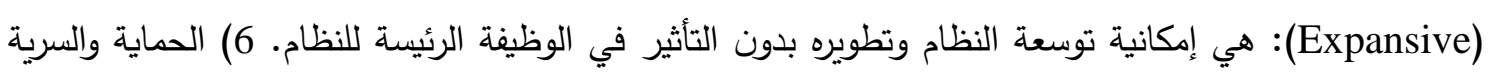
(Security and protection) 
إنَّ للمؤسسات التعليمية والاكاديمية النصيب الأكبر في تطوير أنظمتها التي تعدُ من المؤسسات السباقة

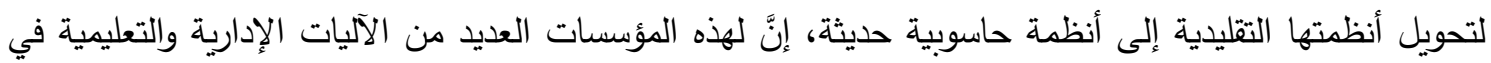

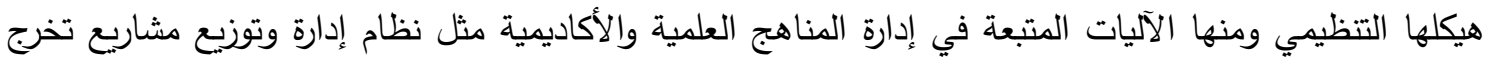

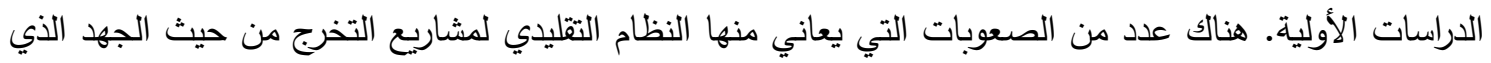

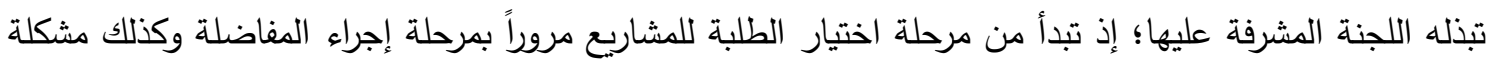
حالة اختيار أكثر من مجموعة من الطلبة للمشاريع نفسها ومتابعتها لحين مرحلة إجراء المناقثة وانتهاءً بإكمال

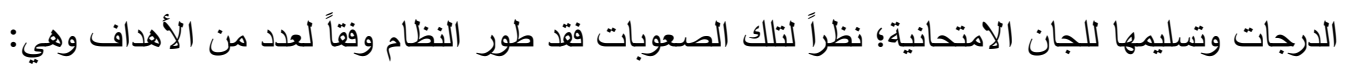
1- بناء نظام يعمل على توزيع المشاريع بصورة سريعة على وفق درجات المفاضلة وإدارته بسهولة وكفاءة عالية. 2- تقليل من الكلفة المادية المترتبة على استخدام الاستمارات الورقية وكلفة طباعتها وآلية حفظها. 3- توفير الجهد والوقت الذي تبذله اللجنة المشرفة على المشاريع. 4- الدقة في عملية جدولة جلسات المناقثات وإصدار القوائم النهائية بسرعة آنية. 5- سهولة استرجاع معلومات وتقييمات المشاريع الطلبة لسنوات سابقة من قاعدة البيانات وبأي وقتا

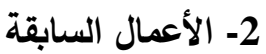

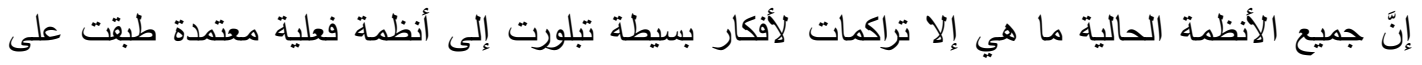

أرض الواقع باختلاف مفهومها التقليدي أو الإككتروني لتلبية إحتياجات المؤسسات التعليمية والتجارية، إلا أنَّ الأنظمة الإكترونية كانت أكثر تأثيراً بما قدمته من كفاءة وسرعة في انجاز المهام الكبيرة التي من الصعب الصغاف انجازها

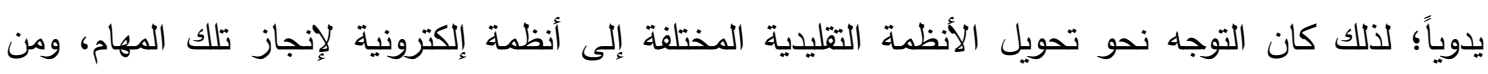
المنظور نفسه طور العديد من الأنظمة الإلكترونية لإدارة مشاريع تخرج طلاب الجامعات وتحويلها من النظام اليدوي إلى نظام إلكتروني باستعمال أساليب وتقانات مختلفة كان منها:

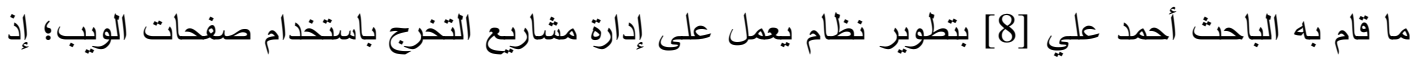
يمكن للنظام إجراء عملية اختيار المشروع وبقية العمليات وبالاعتماد على صفحة خاصة بالنظام التي تتعامل

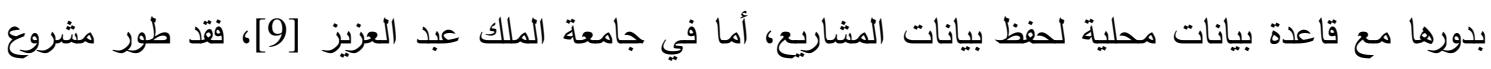

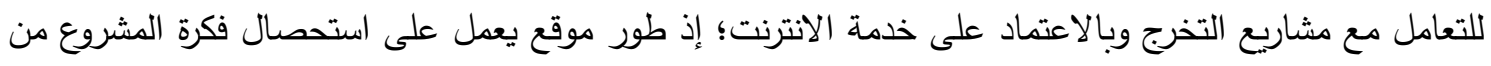

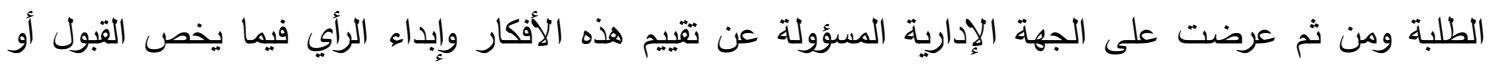

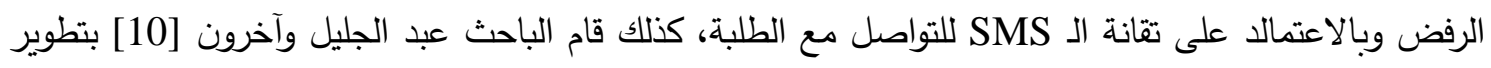
نظام إدارة مشاريع التخرج عن طريق إنشاء عدد من قواعد البيانات تعمل على حفظ المشاريع المقترحة وقاعدة

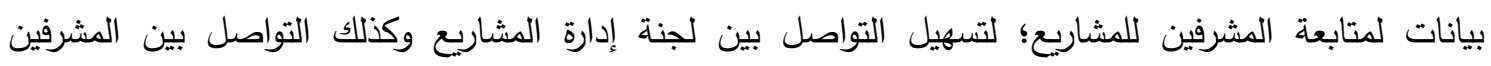
والطلبة. نظام آخر طُوره الفوارعة وآخرون [11] يهدف إلى متابعة مشاريع تخرج طلبة الدراسات الأولية الكترونياً

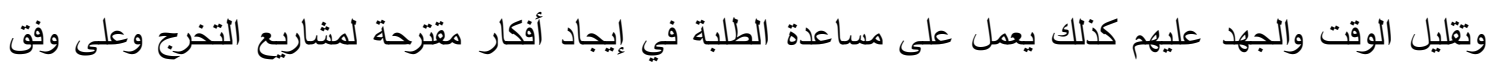

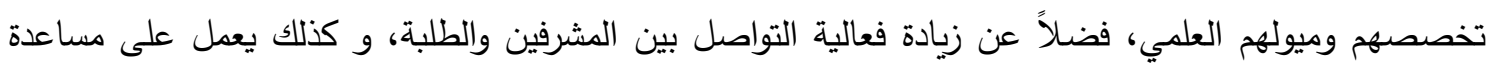

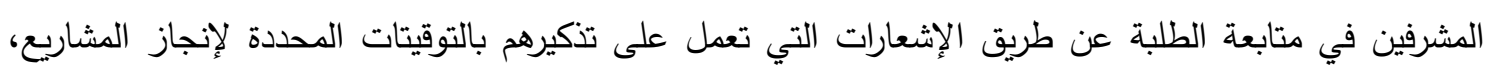
وعمل آخر قدمه أبو صوان وآخرون [12]؛ إذ قاموا بتطوير موقع الكتروني يعتبر مرجعاً للمشاريع السابقة والمحفوظة في المكتبة لتسهيل وصول الطلبة إليها أثناء مرحلة البحث عن أفكار جديدة، وذلك لضمان ونئ عدم تكرار 
الأفكار والبحث عن أفكار جديدة غير مطروقة؛ إذ يعمل الموقع على طرح عدد من الاقتراحات لمشاريع التخرج من

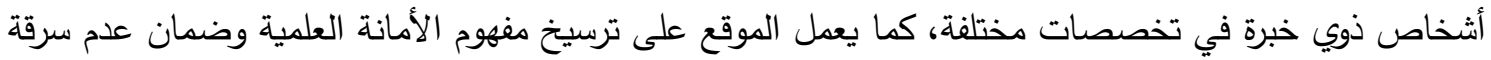
أفكار الدراسات والمشاريع السابقة. ودراسة أخرى قدمها الباحث عادل خليفي وآخرون [13] عملت على تطوير نظام إدارة لمشاريع التخرج عن طريق موقع يقوم بإشاد الطلبة لإنجاز مشاريعهم من خلال اقتراح البرامجيات التي

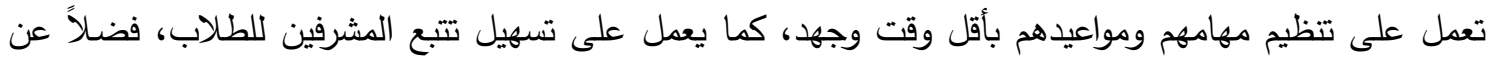
تسهيل مهمة لجنة المشاريع في التأكد من قيام الطلبة بإنجاز المشاريع بالطريقة الصحيحة وعلى وفق الضوابط لهابع

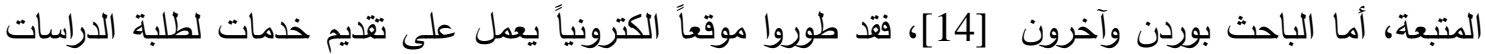
الأولية من حيث تقديم الإرشادات والنصائح لإنجاز مشاريعهم بالصورة الصحيحة، ويوفر الموقع جميع الوثائق والقوالب التي يحتاجها الطلاب لبناء مشاريع بالهيكيلة التي تعتمدها الجامعة، كما يعرض الموقع المشاريع السابقة

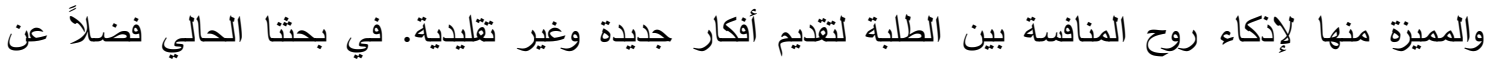
الأعمال السابقة أضيفت إمكانية تقييم لجان المناقثة للرسائل الجامعية وإرسال درجة الطالب للمشروع الى النظام ليقوم مسؤول النظام وإرسال التقارير إلى اللجنة الامتحانية بعد معالجتها.

3 - 3راحل تطوير النظام:

طور النظام المقترح في عدد من المراحل التتظيمية المتبعة في تطوير الأنظمة المعتمدة وهي: 1-3 تحليل متطلبات النظام:

تعدُّ هذه المرحلة من المراحل المهمة والأساسية في تطوير الأنظمة لما تقدمه من أساس صحيح يُعتمد عليه في إنجاز مراحل النظام اللاحقة من تصميم وتتفيذ واختبار للنظام. في هذه المرحلة حلل جميع المتطلبات الوظيفية وغير الوظيفة للنظام فضلاً عن كيفية تمثيل قواعد البيانات وكذلك وصف كافة العمليات التي يقوم بها النظام

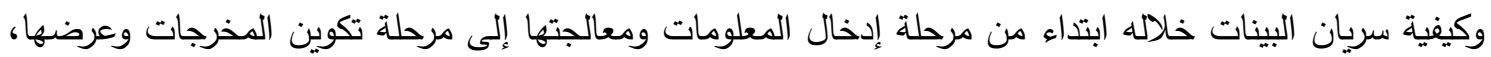
قسمت متطلبات النظام إلى قسمين: متطلبات وظيفية ومتطلبات غير وظيفية.

1-1-3 المتطلبات الوظيفية:

تشمل هذه المتطلبات المهام التي يجب على النظام تأديتها استجابة لمتطلبات الجهات الإدارية في المؤسسة التعليمية وتتمثل بالآتي: أولاً: متطلبات مدير النظام: تثمل متطلبات الخاصة بمدير النظام التي تلخص بالآتي: 1. صلاحية دخول مطلقة إلى جميع أجزاء النظام وباستخدام (اسم دخول وكلمة مرور ). 2. إمكانية تعديل خصائص النظام وتثمل (إضافة، وحذف، والتعديل). 3. صلاحية إدخال بيانات الطلبة من (اسم الطالب، والثعبة ، ونوع الدراسة، والدرجة) إلى قاعدة البيانات. 4. صلاحية إضافة معلومات المشاريع من (عنوان المشروع، وفكرة المشروع، واسم المشرف، واللقب العلمي). 5. إمكانية التعديل على قواعد البيانات من (استحداث، أو حدف، أو تعديل، أو استيراد) 6. صلاحية الاستعلام عن المعلومات التي تخص الطلبة والمشاريع وإعداد التقارير وإصدار النتائج. 7. انشاء حسابات الدخول للمتحنين والمشرف كلاً على وفق صنفه قبل مرحلة المناقثة. 
8. جدولة جلسات المناقثة من حيث اختيار المشروع والطلبة وإرسال صفحة التقييم إلى أعضاء لجنة المناقشة. ثانياً: متطلبات التدريسي: هناك عدد من المتطلبات التي يجب توفيرها للتدريسي سواء كان (ممتحن أو مشرف)

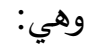
1. امتلاك حساب خاص للدخول إلى النظام وباستعمال (اسم دخول وكلمة المرور) سواء كانت مناقشة أولية أو نهائية.

2. صلاحية التقييم ووضع درجة التقييم للطالب وعلى وفق معايير التقييم المتبعة والمذكورة ضدن صفحة التقييم. 3. صلاحية مزدوجة للتقييم في حالة أن يكون ممتحناً ومشرفاً في الوقت ذاتئ داته.

\section{2-1-3 المتطلبات غير الوظيفية:}

تشمل هذه المتطلبات جميع المعايير العلمية المتبعة في تطوير الأنظمة الإلكترونية ( Electronic systems التي من شأنها أن تجعل النظام أكثر مرونة وأسهل في الاستعمال [15]، ومنها:

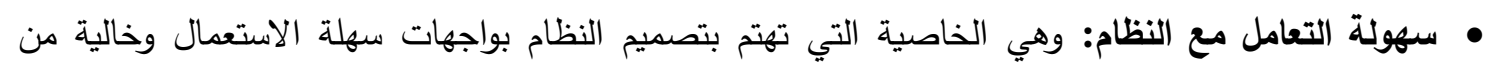

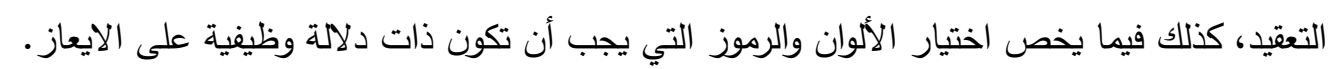

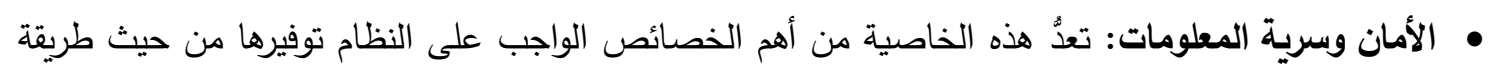

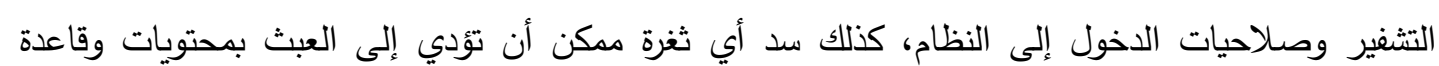
بيانات النظام. • قابلية تعديل النظام وتطويره: تعد من الخصائص المهمة الواجب على النظام توفيرها وتشمل إمكانية تعديل خصائص النظام من حيث أسس تقييم درجة الطالب وكيفية إجراء المفاضلة وغيرها ومن دون إجراء تعديلات كبيرة على النظام، فضلاً عن توفير إمكانية تطوير النظام وإضافة خصائص جديدة عليه مستقبلاً.

2-3 تحليل عمليات النظام (System process analysis)

لإعطاء وصف دقيق لعمليات النظام كان لا بد من استخدام إحدى اللغات المستخدمة في نمذجة عمليات النظام؛ إذ استعملت لغة النمذجة الموحدة UML في تمثيل النماذج وإعطاء وصف متكامل لآلية النظام والعلاقات بين قواعد بيانات النظام مما يسهل عملية تصميم النظام بكفاءة وبدون أخطاء [16][17].

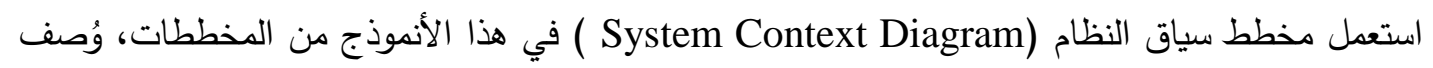

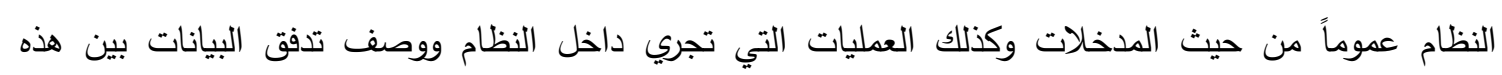

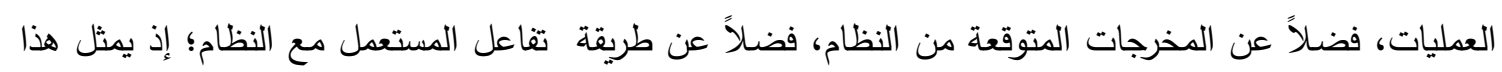

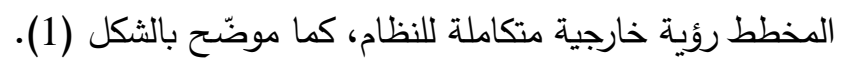




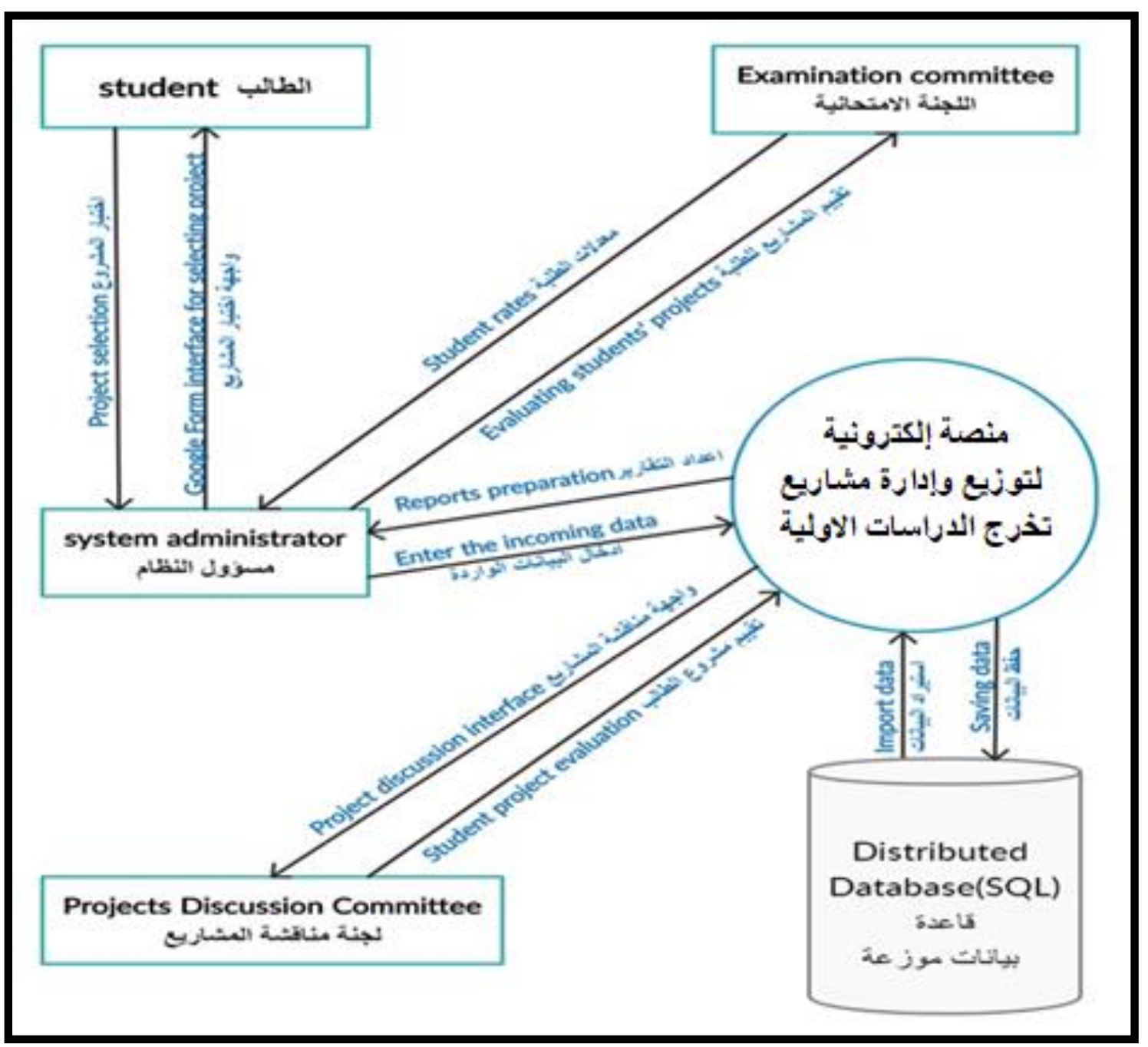

الثكل (1) يوضّح مخطط سياق النظام ( System Context Diagram )

استعمل مخطط حالة الاستخدام (Use Case Diagram) لتوضيح الحالة الوظيفية وصلاحيات مستخدمي

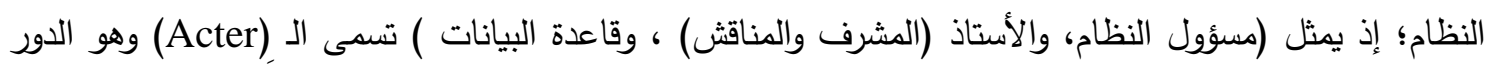

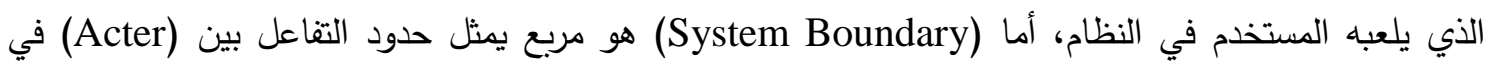

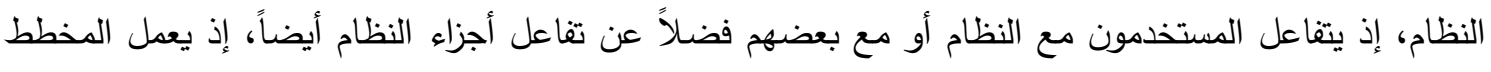

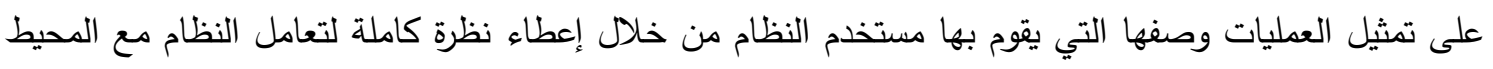

الخارجي ويوضح طبيعة العلاقات ما بين العمليات داخل النظام، كما موضّح في الثكل (2) لئّل 


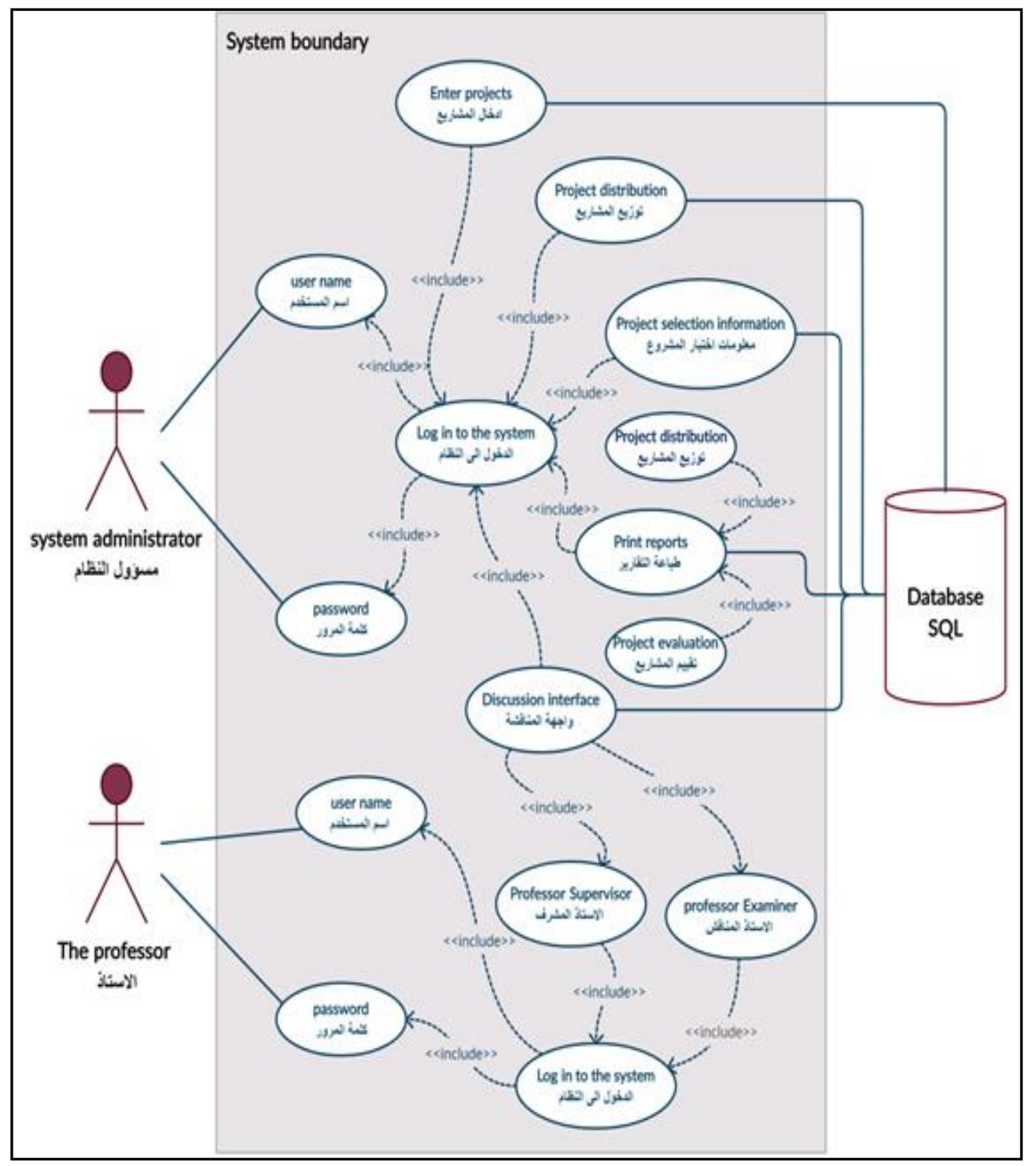

الثكل (2) يوضّح مخطط حالة الاستخدام (Use Case Diagram)

3-3 تصميم قاعدة بيانات النظام:

بعد الانتهاء من مرحلة تحليل متطلبات النظام تبدأ عملية التصميم التي تتضمن تصميم قاعدة البيانات الرئيسة الخاصة بالنظام، تتكون قاعدة بيانات النظام من أربعة جداول رئيسة لكل منها عدد من الحقول تضم اسم الخاصية والوظيفة التي تمثلها هذه الخاصية وعلى النحو الآتي: أولاً: قاعدة بيانات معلومات المشاريع: يتضمن هذا الجدول جميع المعلومات الخاصة بالمشاريع من حيث اسم

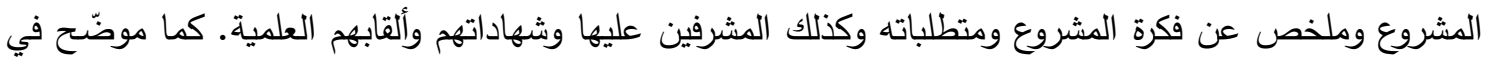

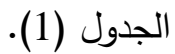
ثانياً: قاعدة بيانات المشاريع بعد التوزيع: يتضمن هذا الجدول جميع المعلومات الخاصة بالمشاريع الموزعة بعد

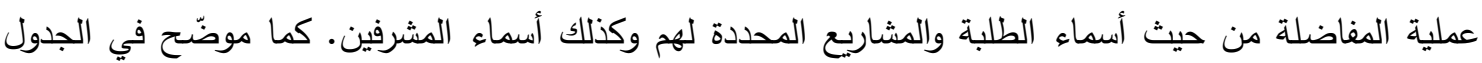




\begin{tabular}{|c|c|c|c|}
\hline \multicolumn{2}{|c|}{ الجدول (2) يوضّح معلومات توزيع المشاريع } & \multicolumn{2}{|c|}{ لجدول (1) يوضّح قاعدة بيانات معلومات المشاريع } \\
\hline الوظيفة & اسم الحقل & الوظيفة & اسم الحقل \\
\hline اسم الطالب & Sname & اسم المشروع & Pname \\
\hline نوع دراسة الطالب & Sstudy & اسم المشرف على المشروع & Psuper \\
\hline شعبة الطالب & Sdass & اللقب العلمي للمشرف & Psuperaddress \\
\hline المشروع المحدد للطالب بعد المفاضلة & Sproject & مجال التوجه للمشروع ل & Pscope \\
\hline اسم الأستاذ المشرف على الطالب & Ssuperviser & ملخص فكرة المشروع & Pabstruct \\
\hline اللقب العلمي للمشرف & Ssupervsoradd & متطلبات المشروع & Prep \\
\hline
\end{tabular}

ثالثاً: قاعدة بيانات اختيارات الطلبة: يشمل هذا الجدول المعلومات الخاصة باختيارات الطلبة للمشاريع؛ إذ يتضمن الجدول اسم الطالب ونوع الدراسة وكذلك شعبة الطالب فضلاً عن مشاريعهم المختارة وكما موضح في فئان الجدول

الجدول(3) قاعدة بيانات اختيارات الطلبة

\begin{tabular}{|c|c|c|c|}
\hline الوظيفة & اسم الحقل & الوظيفة & اسم الحقل \\
\hline الإختيار الخامس من المشاريع & Fifthproject & اسم الطالب الاول & Name1 \\
\hline الإختيار السادس من المشاريع & Sixthproject & اسم الطالب الثاني & Name2 \\
\hline الإختيار السابع من المشاريع & Seventhproject & اسم الطالب الثالث & Name3 \\
\hline الإختيار الثامن من المشاريع & Eighthproject & نوع الدراسة (صباحية ام مسائية) & Study \\
\hline الشعبة للطالب الاول & Dass1 & الإختيار الاول من المشاريع & Firstproject \\
\hline الثعبة للطالب الثاني & Dass2 & الاختيار الثاني من المشاريع & Secndproject \\
\hline الشعبة للطالب الثالث & Dass3 & الاختيار الثالث من المشاريع & Therdproject \\
\hline
\end{tabular}

رابعاً: قاعدة بيانات مستعملي النظام: يتضمن هذا الجدول المعلومات الخاصة بمستعملي النظام من حيث اسم

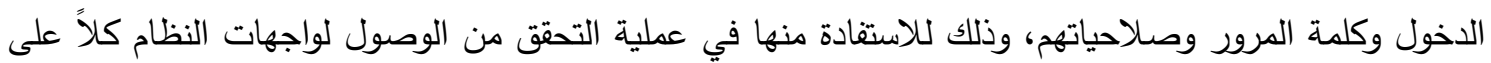
وفق صنفه. كما موضّح في الجدول (4).

\begin{tabular}{|c|c|}
\hline الوظيفة الو & اسم الحقل \\
\hline 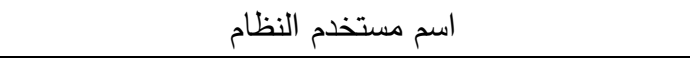 & :Uname \\
\hline كلمة مرور مستخدم النظام & :Upass \\
\hline نوع مستخدم النظام ( مسؤول اللجنة، مشرف او مناقش) & :Ulevel \\
\hline
\end{tabular}

4-3 تصميم هيكلية النظام:

اعتمد مفهوم الخادم/ الزبون (Clien-Server) كصيغة معمارية للتصميم الهيلكي للنظام التي تعدُ أحد مفاهيم الأنظمة الموزعة؛ إذ يعمل فيها الجهاز الرئيس على خدمة الأجهزة الثانوية الأخرى، يتألف النظام المقترح من حاسوب مركزي الذي يعمل خادماً لبرنامج النظام الرئيس وعدد من أجهزة مستعملي النظام التي تعمل كزبائن لذلك الخادم؛ لتحقيق الاتصال بين هذه الأجهزة، اعتمد على تقانة الوايفاي (WiFi) في عملية التصال التهال الأجهزة 
وتناقل البيانات، يقوم جهاز الخادم في هذا النظام الذي يديره مسؤول لجنة المشاريع والذي يمثل الجهة المسؤولة

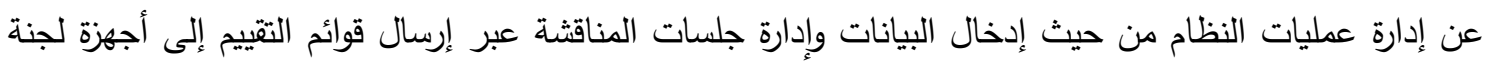
المناقثة والمشرف ومن ثم استلام النتائج منهم وتكوين القوائم النهائية لدرجات الطلاب وتسليمها إلى اللجنة

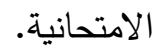
واستتاداً إلى الأسس المتبعة في عملية مناقثة المشاريع فإنَّ هنالك عدداً من المثتحنين والمشرف ومسؤول

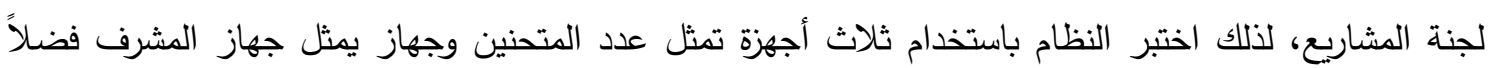
عن حاسوب مسؤول النظام كما موضح بالثكل (3)؛ حيث يقوم الأخير بإدارة عملية المناقثة ابتداءً من تكوين

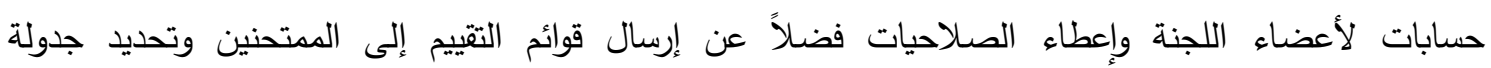
المناقثات وانتهاءً بطباعة القوائم وتسليمها إلى اللجنة الامتحانية.

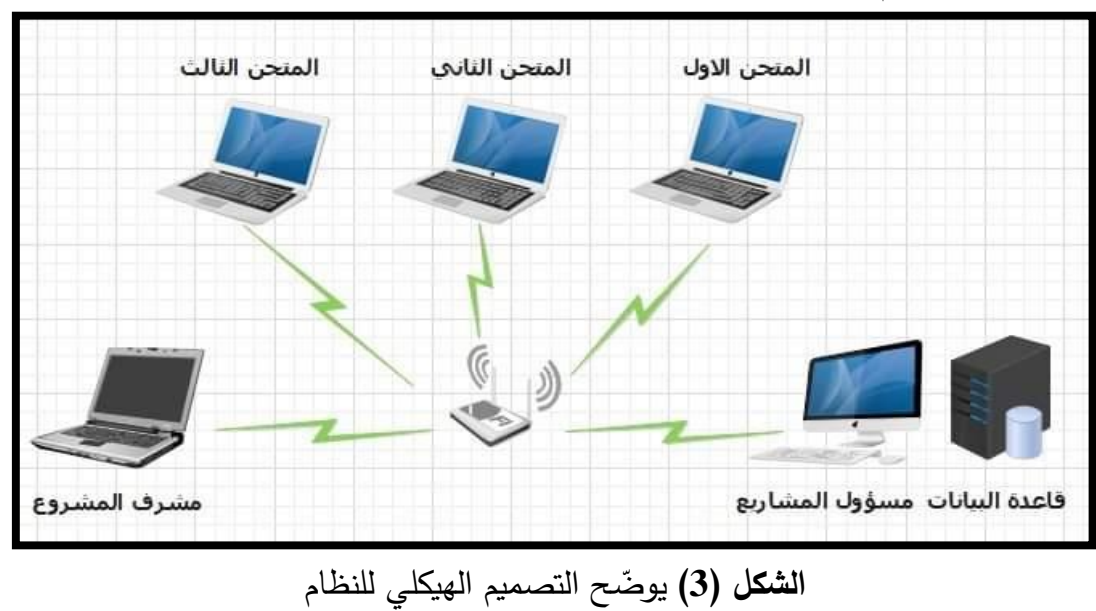

5-3 المخطط الرئيس للنظام:

يوضّح الثكل (4) المخطط الانسيابي العام لسير عمليات النظام الرئيسة التي يمكن تلخيصها بالنقاط الآتية: 1. يتم دخول النظام بعد التأكد من صحة معلومات الدخول وكذلك صفة المستخدم. 2. البيات التي يطلب من مسؤول النظام إدخالها:

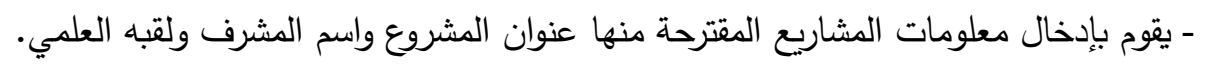

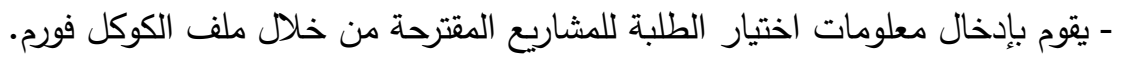
- يقوم النظام بإجراء عملية المفاضلة وبالاعتماد على قوائم المشاريع واختيارات الطلبة وعلى وفق معدل لاتهم.

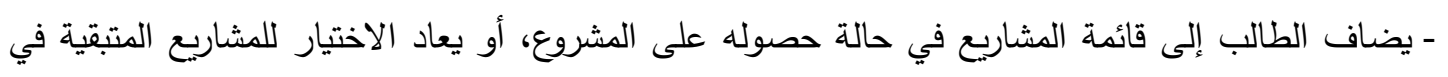
حالة عدم حصوله على مشروع من المفاضلة الأولى. 3. دخول المتحن للنظام يكون ضمن حالتين: - دخوله للمناقثة الأولية: في هذه الحالة يقوم الممتحن باختيار اسم المشروع بعد الدخول إلى صفحة المناقثة

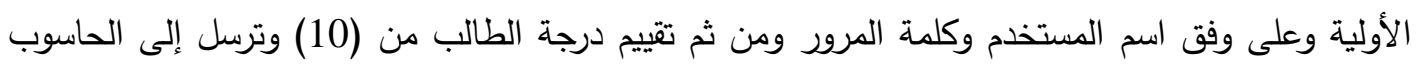


- دخول لمناقثة النهائية: في هذه الحالة يقوم المتحن باختيار اسم المشروع بعد الدخول إلى صفحة المناقثة

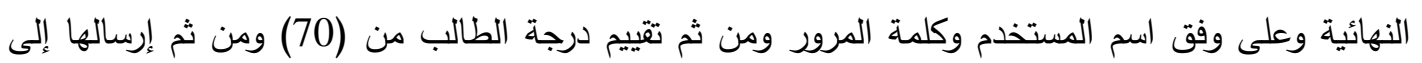

$$
\text { الحاسوب المركزي. }
$$

4. دخول مشرف المشروع: يقوم المشرف باختيار اسم المشروع بعد الدخول إلى صفحة المناقثة الخاصة بالأستاذ

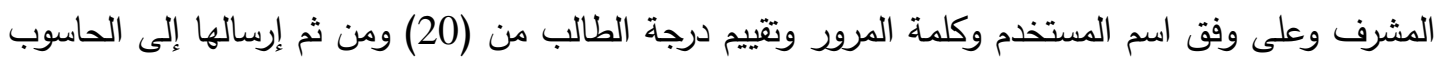

5. بعد إجراء المناقشة يقوم النظام بجمع الدرجات الثلاث (درجة المناقثة الأولية، ودرجة المشرف، ودرجة المتحن 6ي المناقثة النهائية) ومن ثم إصدار الدرجة النهائية للطالب التي تكون من (100) درجة. 6. يقوم النظام بإنشاء قوائم بأسماء الطلبة ومعدلاتهم وطباعتها. 7. إرسال القوائم النهائية إلى اللجنة الامتحانية.

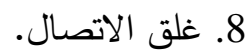

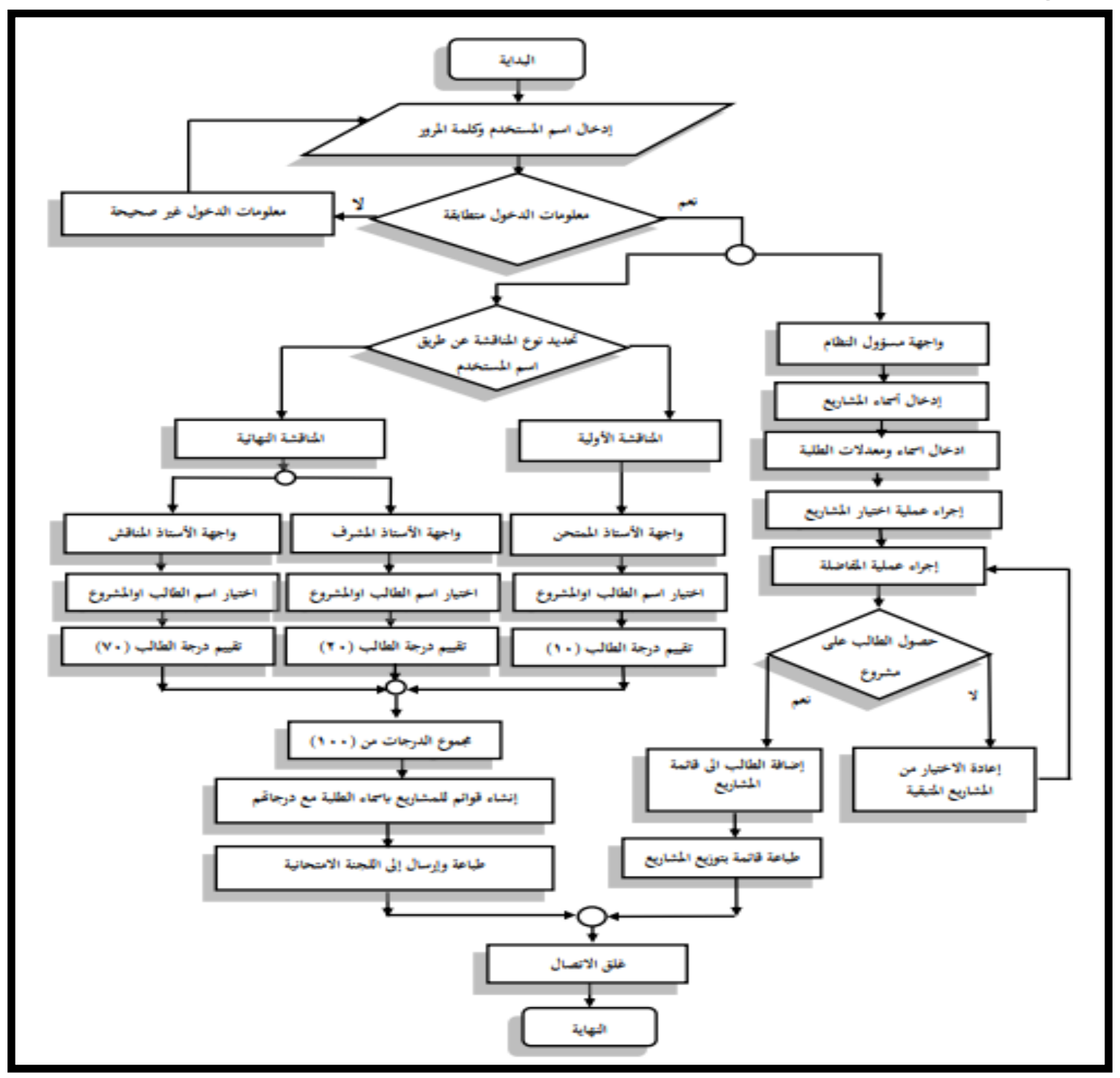

System Flowchart الثكل (4) يوضتح المخطط العام للنظام 
6-3 احتساب معدل الطالب:

تحتسب درجة الطالب النهائية بالاعتماد على مجموع درجات أعضاء لجنة المناقثة الأولية والبالغ عددهم

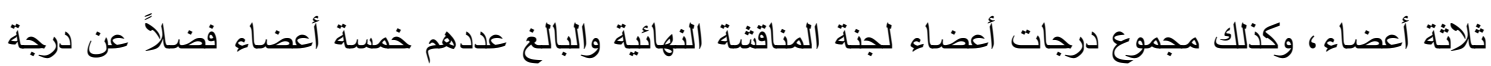
المشرف. توضح النقاط التالية طريقة احتساب هذه الدرجات وإيجاد الدرجة النهائية: 1- يقوم الممتحنون الثلاثة في المناقثة الأولية بتقييم الطالب من (10) درجات لكن لكل ممتحن، تجمع الدرجات

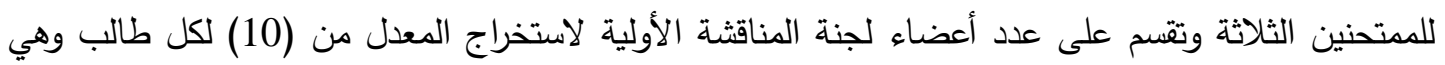
تمثل درجة المناقشة الأولية. 2- يقوم الممتحنون الخمسة في المناقثة النهائية بتقييم الطالب من (70) درجة لكل ممتحن، تجمع الدرجات للممتحنين الخمسة وتقسم على عدد أعضاء لجنة المناقثة النهائية لاستخراج المعدل من (70) لكل طالب وهي تمثل درجة المناقشة النهائية. 3- يقوم المشرف بتقييم درجة الطالب من (20) درجة. 4- تجمع الدرجات في الخطوات (1، 2، 3) وإيجاد الدرجة الكلية لتقييم الطالب من (100) درجة وإعطاء التقدير

يدخل المستخدمون عن طريق الاتصال بالشبكة الداخلية (WiFi) وتتم بطريقتين: 1- الطريقة الأولى: إما يتم إعداد (setup) النظام على حاسبة المستخدمين وبمجرد ربط الجهاز بالشبكة الداخلية وتشغيل النظام سوف تظهر نافذة تسجيل الدخول مباشرة والاخول إلى قاعدة البيانات الرئيسة وعلى (WiFi)

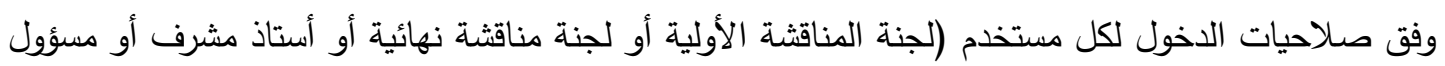
نظام). 2- الطريقة الثانية: يمكن دخول لجنة المناقثة أيضاً عن طريق متصفح الانترنيت في الحاسوب أو الموبايل بعد الاتصال بالشبكة الداخلية (WiFi) وكتابة مقبس الخادم (Raw Socket) في محور البحث وهو (192.168.0.160:8080) الخاص بعملية الاتصال الذي يعده مسؤول النظام لتظهر صفحة ويب لتسجيل

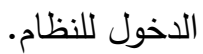
8-3 تصميم واجهات النظام:

صمم النظام بعدد من الواجهات الخاصة بكل عملية وعلى وفق صفة مستخدم النظام، منها ما هو خاص بمسؤول النظام ومنها واجهة الممتحن وكذلك واجهة المشرف؛ لذلك سيعرض على لونى هذه الواجهات، وماهي وظيفة كل منها؟ والأوامر الخاصة بها: 1-8-3 واجهة الاخول الرئيسة:

وهي الواجهة التي ينتقل بها إلى واجهات النظام الفرعية الأخرى التي تحدد على وفق صلاحيات المستخدم

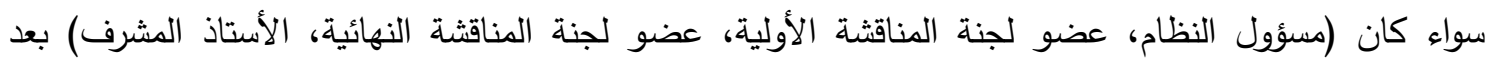
الاتصال بالثبكة الداخلية وكتابة مقبس الخادم (Raw Socket) وهو (192.168.0.160:8080) الخاص بعملية

الاتصال في المتصفح وذلك باستخدام (اسم المستخدم وكلمة المرور)، كما في الثكل (5). 


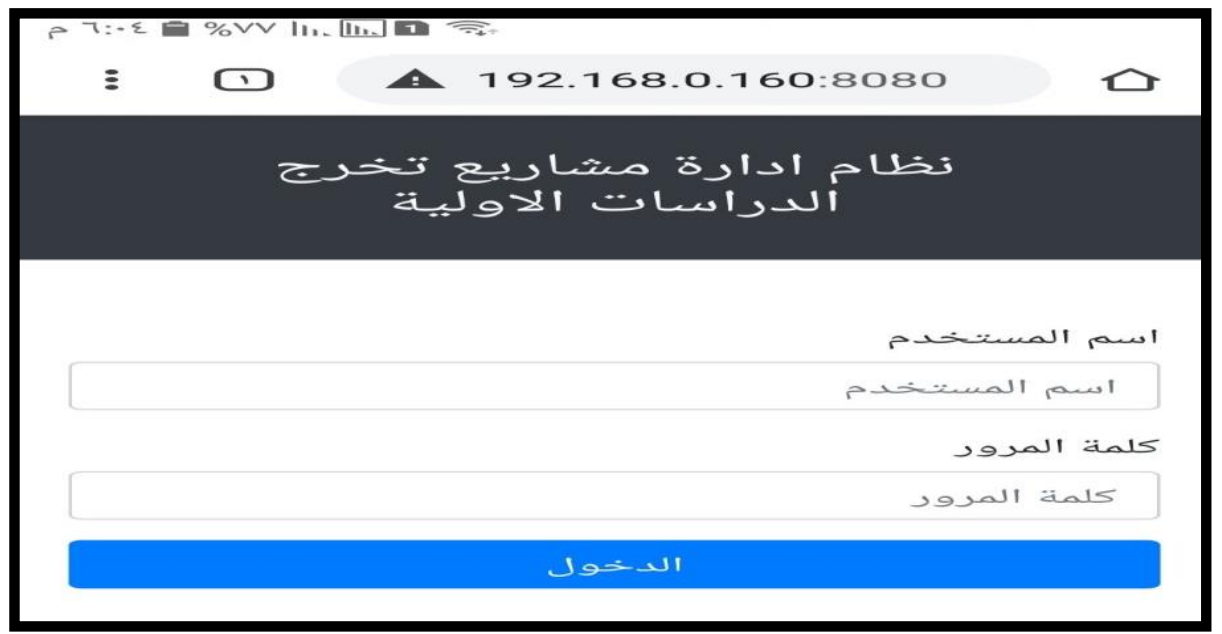

الشكل (5) يوضّح واجهة الدخول للنظام

2-8-3 2 2-3 20نة مؤول النظام:

تمثل هذه الواجهة من أهم واجهات النظام التي يديرها مسؤول لجنة المشاريع، يتم بها إتمام جميع مهام النظام ابتداء من عملية إدخال بيانات المشاريع والطلبة إلى النظام وانتهاء بطباعة التقارير وتسليمها إلى اللجنة الامتحانية.

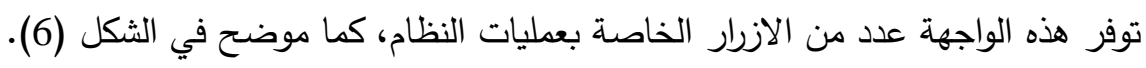

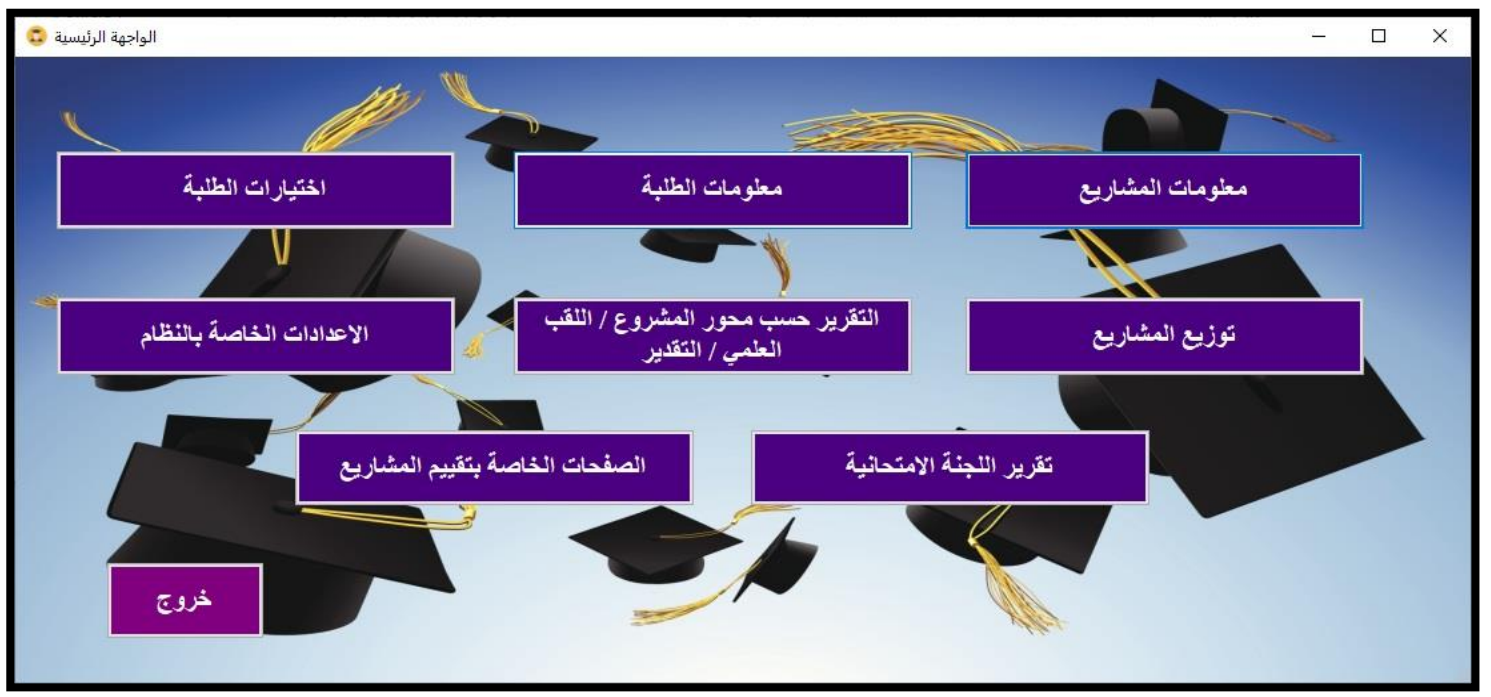

$$
\text { الثكل (6) يوضّح واجهة النظام الرئيسية }
$$

تتبثق من واجهة مسؤول النظام واجهات كثيرة تعنى بإدارة أو ضبط النظام، منها واجهة إدخال معلومات

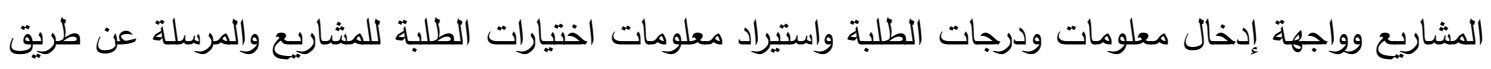

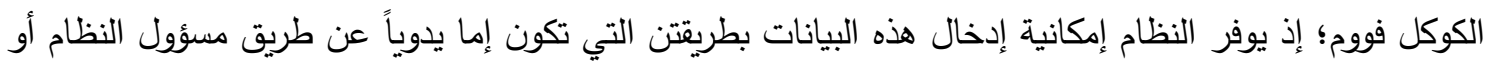

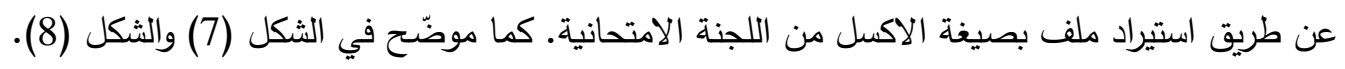




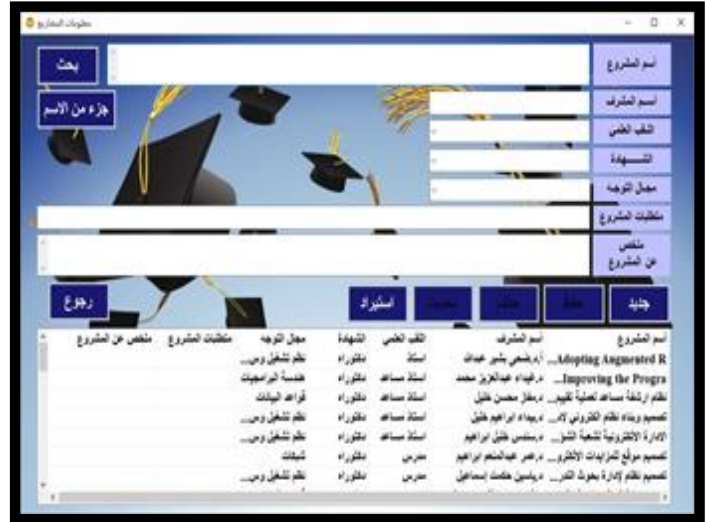

الثكل (8) يوضّح واجهة معلومات الطلبة

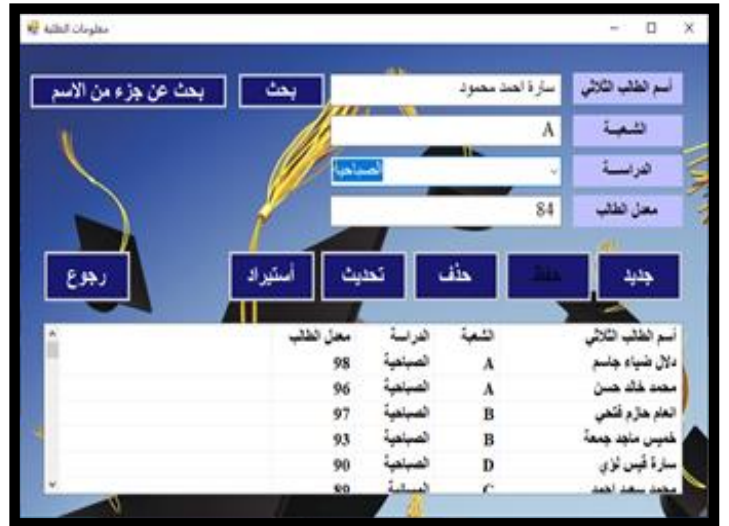

الثكل (7) يوضّح واجهة معلومات الطلبة

وكذلك ينبثق من واجهة مسؤول النظام واجهات لإعداد التقارير حول محور المشاريع وكذلك تقرير حول الطلاب وعلى وفق التقييم للبحث وتقرير حول الأساتذة المشرفين على المشاريع وعلى وفق اللقب العلمي، لاحظ

(9) الشكل

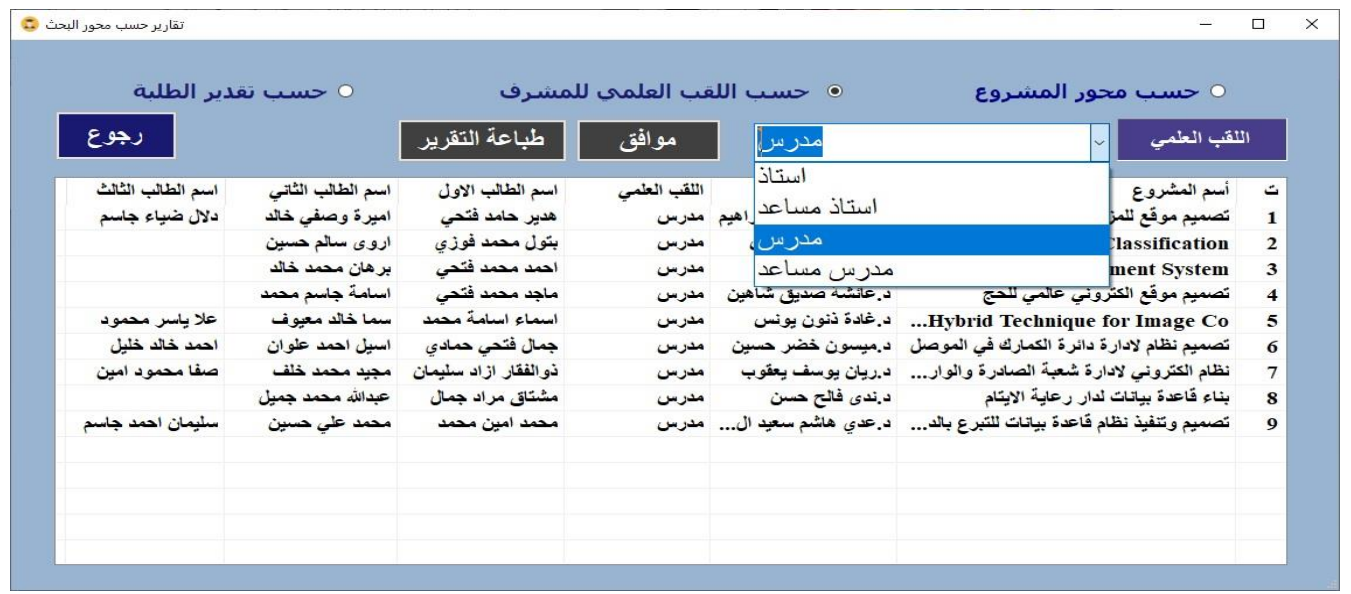

$$
\text { الثكل (9) يوضّح واجهة إعداد التقارير }
$$

وعند الضغط على زر ضبظ النظام تتبثق واجهة أخرى لتنظيم وإصدار اسم وكلمة المرور الممنوحة للمستخدمين كل على وفق صنفه، وهنالك واجهة لحفظ قاعدة بيانات النظام واسترجاعها في حال الحاجة إليها مستقبلاً، لاحظ الثكل (10) والثكل (11).

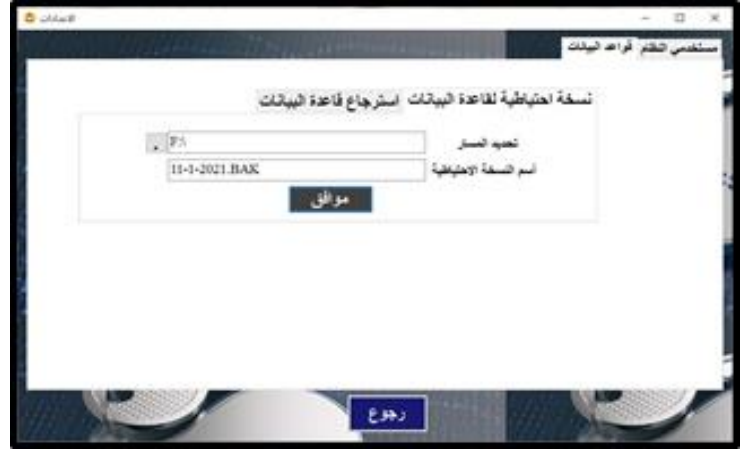

الثكل (11) يوضّح واجهة حفظ واسترجاع قاعدة البيانات

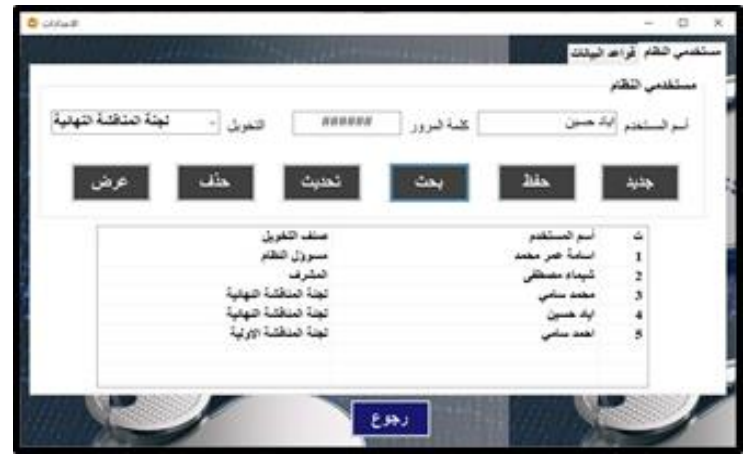

الثكل (10) يوضّح واجهة منح اسم وكلمة المرور 


\section{3-8-3 واجهة لجنة المناقشة الاولية:}

توفر هذه الواجهة عملية تقييم الطلبة أثثاء المناقثة الأولية، يقوم فيها ثلاث مدتحنين بتقييم كل طالب في المجموعة على وفق أسس معينة وبدرجة (10\%) من درجة المشروع الكلية، يحدد مسؤول النظام معلومات الدخول

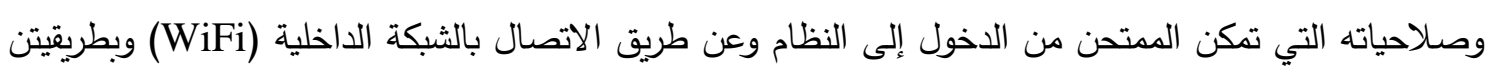

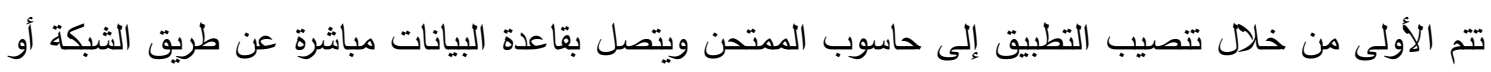
يمكن الوصول إلى واجهة التقييم عبر صفحة الويب الخاصة بالنظام بعد الاتصال بالثبكة الداخلية وكتابة مقبس ولتصن الخادم (Raw Socket) وهو (192.168.0.160:8080) الخاص بعملية الاتصال في المتصفح بجهاز الموبايل

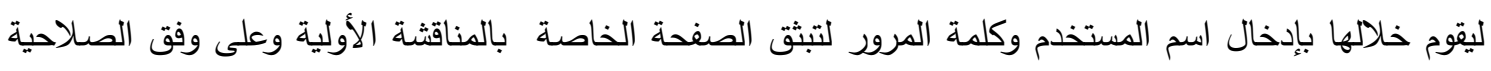
التي يمنحها مسؤول النظام، ويقوم الممتحن لاختيار أحد المشاريع، ثم ينتقل إلى صفحة التقييمات التي تمكن لتحن المتحن من ملء الحقول الخاصة بدرجات التقييم ليتم بعدها إرسال الدرجة إلى قاعدة البيانات الرئيسة للنظام عبر شبكة الاتصال اللاسلكية، يوضح الثكل (12) والثكل (13) هذه الواجهات.

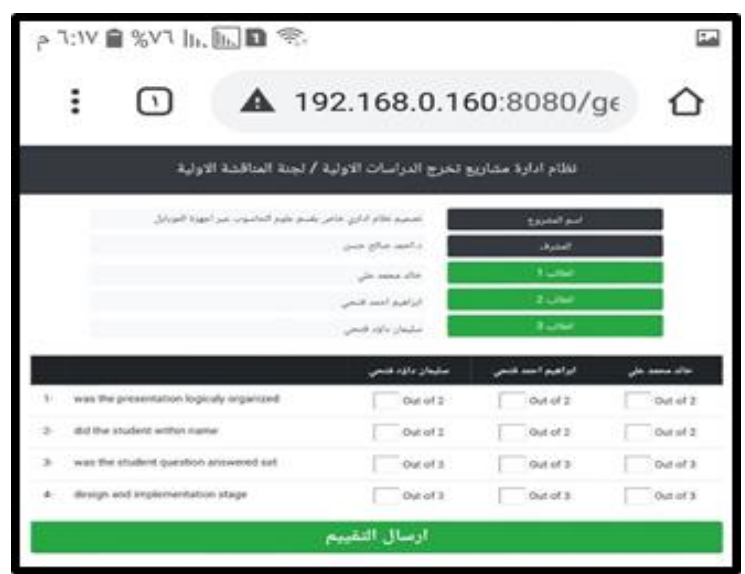

الثكل (13) يوضّح واجهة تقييم المناقثة الأولية للطلبة

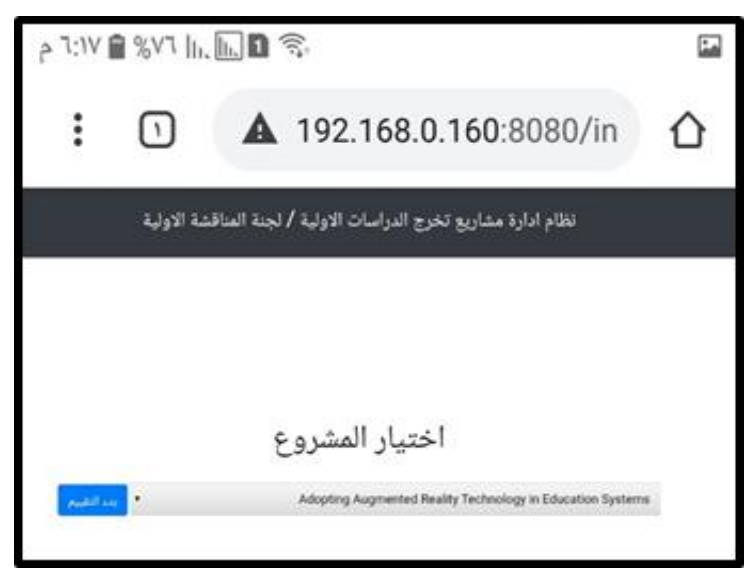

الثكل (12) يوضّح واجهة اختيار المشرع للمناقثة الأولية

\section{4-8-3 واجهة لجنة المناقثة النهائية:}

تستخدم هذه الواجهة في عملية تقييم الطلبة أثناء مرحلة المناقثـة النهائية التي يقوم بها خمسـة ممتحنين وبدرجة (• • من درجة المشروع الكلية، حدد مسؤول النظام معلومات الدخول وصلاحياته التي تمكن الممتحن من الدخول إلى النظام عن طريق الثبكة الداخلية (LAN) باستخدام تقانة الاتصـال اللاسلكي (WiFi) وبطريقيتن تتم الأولى من خلال تتصيب التطبيق إلى حاسوب الممتحن ويتصل بقاعدة البيانات مباشرة عن طريقة الشبكة ،

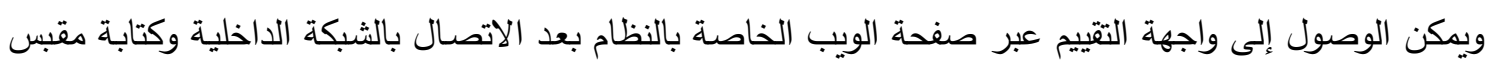
الخادم (Raw Socket) وهو (192.168.0.160:8080) الخاص بعملية الاتصال في المتصفح، ليقوم بإدخال اسم المستخدم وكلمة المرور لتبثق الصفحة الخاصة بالمناقثة النهائية وعلى وفق الصـلاحية التي يمنحها مسؤول

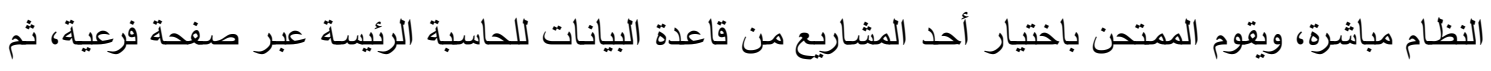
ينتقل إلى صفحة التقييمات التي تمكن الممتحن من مله الحقول الخاصة بدرجات التقييم ليتم بعدها إرسال التقييم

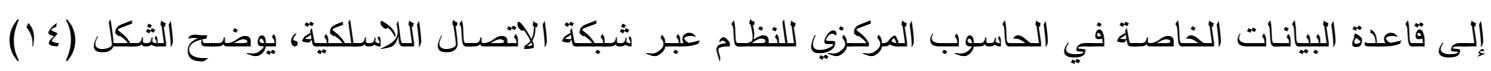
والثكل (10). 


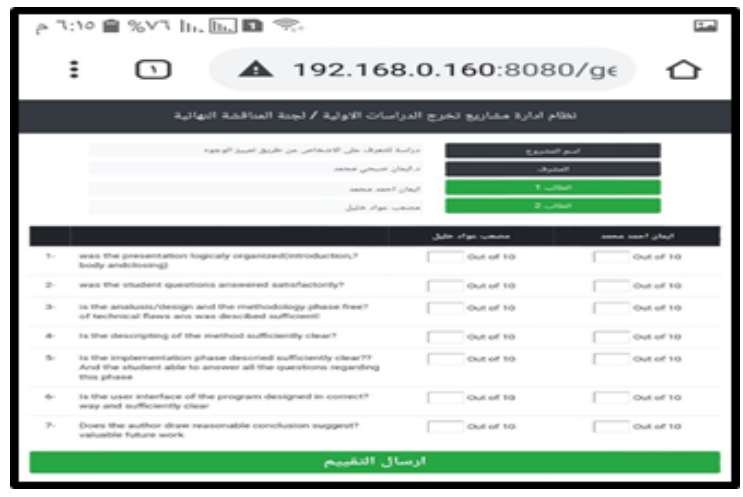

الثكل (15) يوضّح واجهة تقييم المناقشة النهائية للطلبة

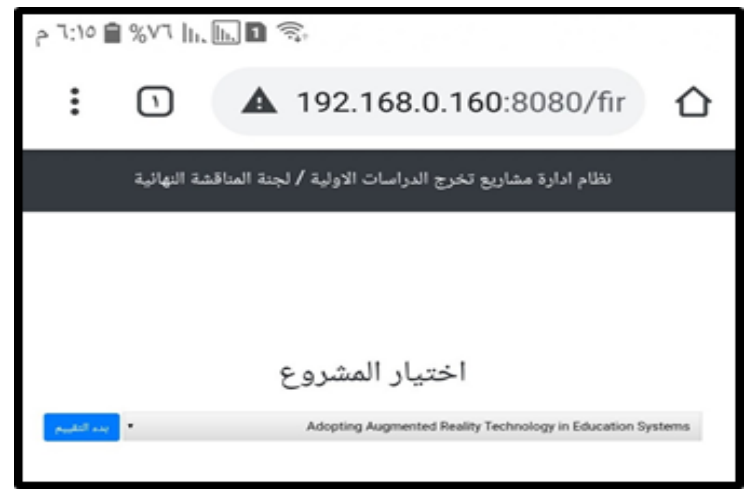

الثكل (14) يوضّح واجهة اختيار الشرع للمناقثة النهائية

كما هو الحال في الواجهات الخاصة بالممتحنين للمشرف أيضاً واجهة يقوم من خلالها بتقييم الطلبة الذين هم

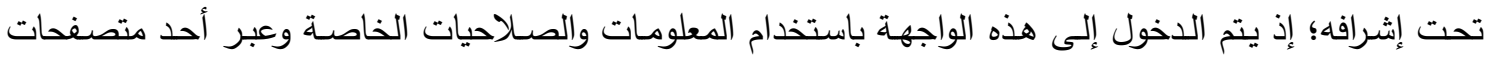
الويب الخاصـة بجهاز الموبايل الخاص بالمشرف. تكون درجة التقييم الخاصـة بالمشرف من (20\%) من الدرجة الدهات

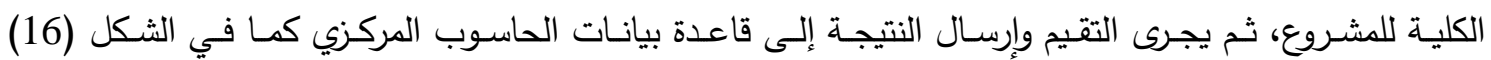

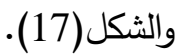

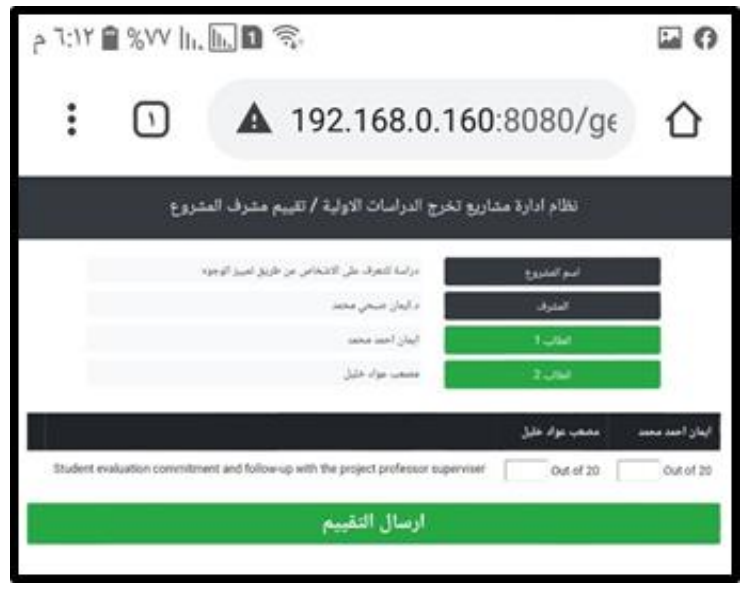

الشكل (17) يوضّح واجهة تقييم المشرف للطلبة

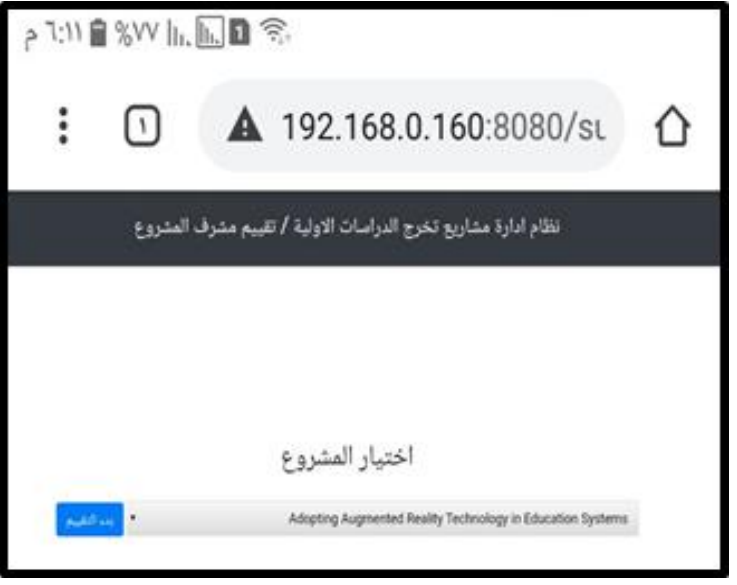

الثكل (16) يوضّح واجهة اختيار المشرع لمناقثة المشرف

$$
\text { 9-3 نتائج وتقارير النظام: }
$$

بعد إكمال عملية التقييم للطلبة عن طريق لجان المناقثـة وإرسالها إلى قاعدة البيانات المركزيـة سوف يقوم مسؤول النظام بتتظيم البيانات ومعالجتها عن طريق النظام لإصدار النتائج والتقارير وعلى النحو الآتي: 1-9-3 نتائج الطلبة المرسلة إلى اللجنة الامتحانية:

يقوم مسؤول النظام بتكوين تقرير خاص بأسماء ودرجات الطلبة وتقديراتهم في المشاريع المعينة التي ينظمها

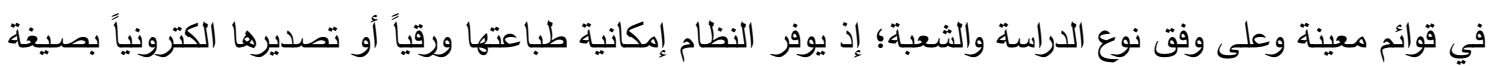
ملف ورد أو اكسل وإرسالها إلى اللجنة الامتحانية، يوضـح الثكل (18) واجهة التقارير الخاصـة بالنتائج، ويوضّح الثكل (19) أنموذج التقرير الخاص باللجنة الامتحانية ولثعبة معينة ضمن الدراسة الصباحية. 


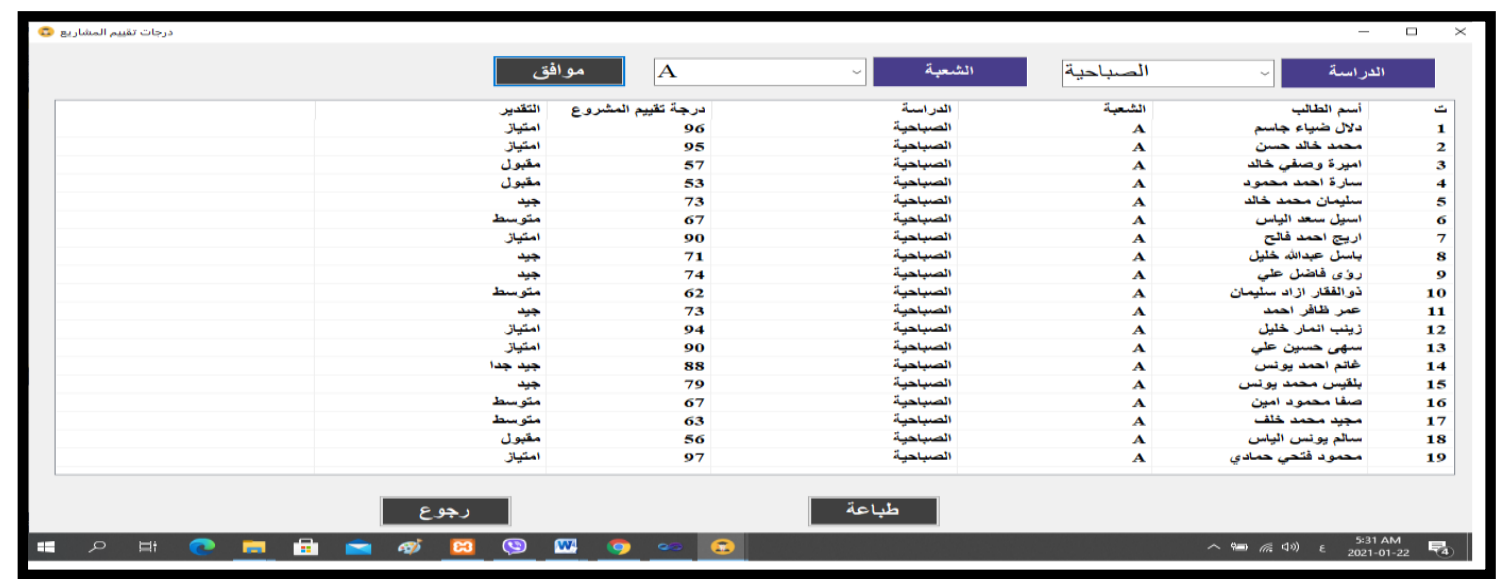

الثكل (18) يوضّح واجهة اصدار نتائج تقييم المشاريع للطلبة

\begin{tabular}{|c|c|c|c|c|c|}
\hline \multicolumn{6}{|c|}{ 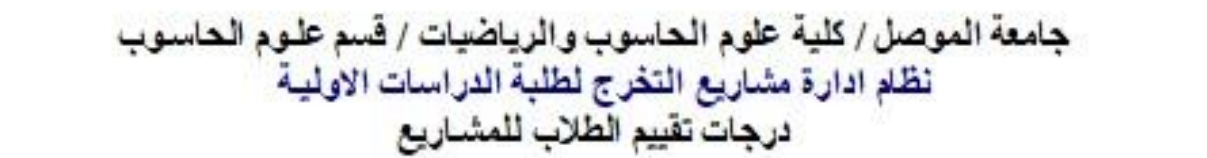 } \\
\hline & A & الثبة & & لموعالناسة & \\
\hline الثتير & نرجة المتيث & الناست & المببة & أسد الثلب & $=$ \\
\hline أمباز & 96 & الصباحبـإِ & A & دلال ضطباء جائمت & 1 \\
\hline المبهاز & 95 & الصباحبي & A & محمدخال حسن & 2 \\
\hline متبول & 57 & الصباحبـا & A & 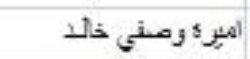 & 3 \\
\hline مقتول & 53 & الصباحبك & A & سارك احمد محمود & 4 \\
\hline جبا: & 73 & الصباحبـاء & A & 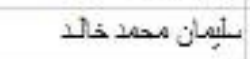 & 5 \\
\hline 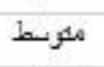 & 67 & الصباحبي & A & البل سعد البيان & 6 \\
\hline المباز & 90 & المباحبيد & A & الريج أحمديدالح & 7 \\
\hline جي & 71 & الصبأبيا: & A & 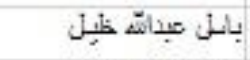 & 8 \\
\hline جبل & 74 & الصباحبيد & A & رؤى ثاهنل طي & 9 \\
\hline ملمزبط & 62 & الصباحبيد & A & دوالتتار ازلد بـلبيمان & 10 \\
\hline جب & 73 & المباحبيد & A & عمر ظائر احمد & 11 \\
\hline أمبهاز & 94 & العباحثيد & A & زيسب العاز خلبل & 12 \\
\hline امبعاز & 90 & الصباحبيك & A & بهى حسبن ثلى & 13 \\
\hline جلا جنا & 88 & الصباحبا & A & ثائم إحما بـرونس & 14 \\
\hline جب & 79 & الصباحبـإ & A & ئبقِّ محمد بروس & 15 \\
\hline ملمنط & 67 & الصباحبيا & A & 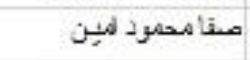 & 16 \\
\hline ملمونط & 63 & الصباجباء & A & مجيد محمد ظلب & 17 \\
\hline متبول & 56 & الصباحبي & A & سلم بونس الباسن & 18 \\
\hline المهباز & 97 & الصباحسيد & A & مصمود الحمي حماذئي & 19 \\
\hline
\end{tabular}

الثكل (19) يوضّح تقييم طلبة احدى شعب الدراسة الصباحية المرسل الى اللجنة الامتحانية 
2-9-3 تقارير النظام:

للنظام إمكانية تكوين عدد مختلف من التقارير وعلى وفق محددات الجهات الإداريـة أو مسؤول النظام؛ إذ

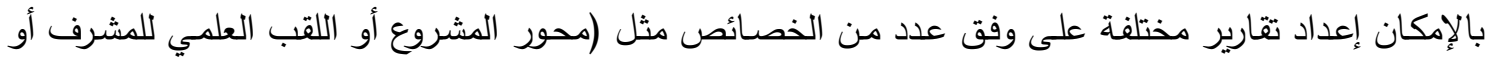

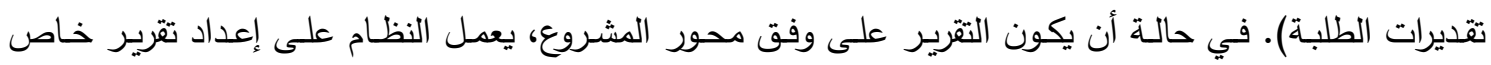
بالمشاريع التي تكون ضمن محور معين مثل (محور معالجة الصور، محور قواعد البينات، محور الثبكات...إلخ) وكما في الشكل (20). أما في حالة أن يكون التقرير على وفق اللقب العلمي، فإنَّ النظام يعمل على إعداد تقرير

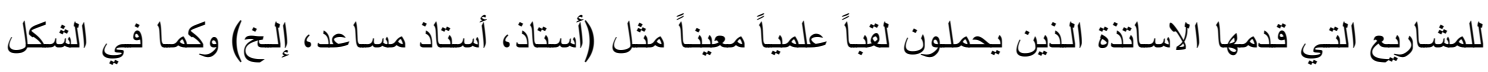

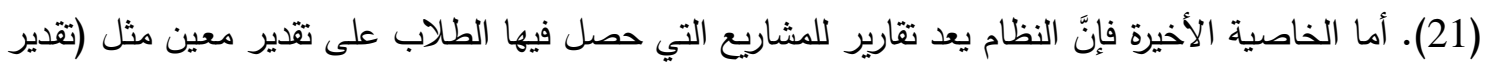
الامتياز , تقدير جيد جداً... إلخ) كما في الثكل (22).

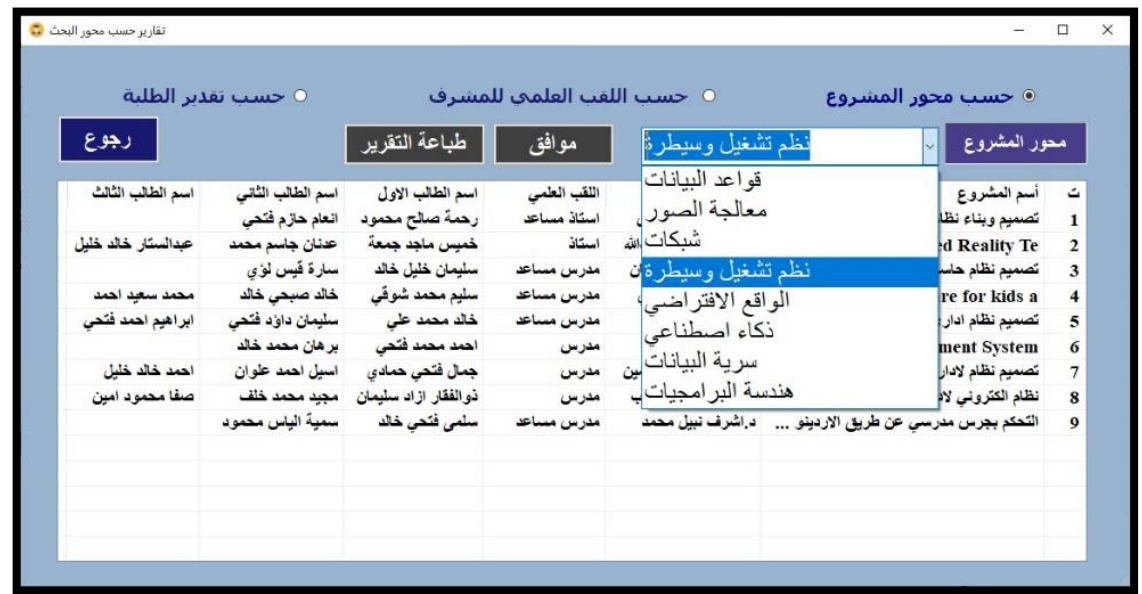

الثكل (20) يوضّح إعداد التقرير حسب محور المشروع

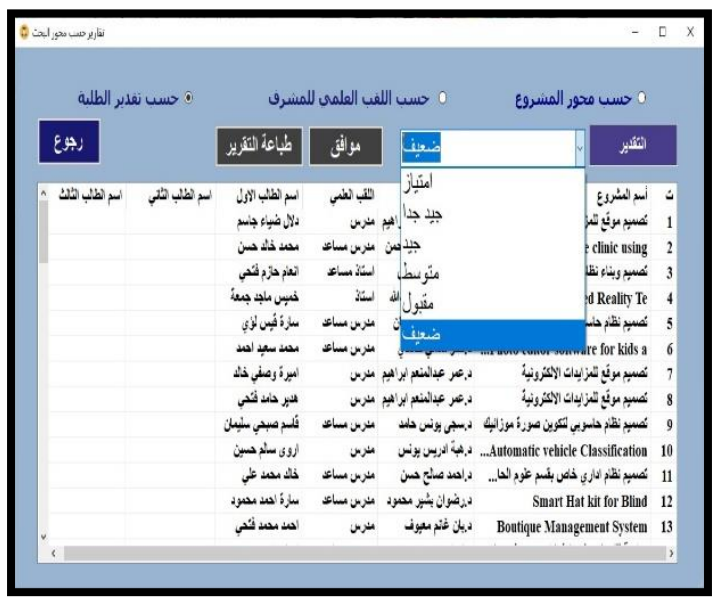

الثكل (22) يوضّح إعداد تقرير حسب تقديرات الطلبة

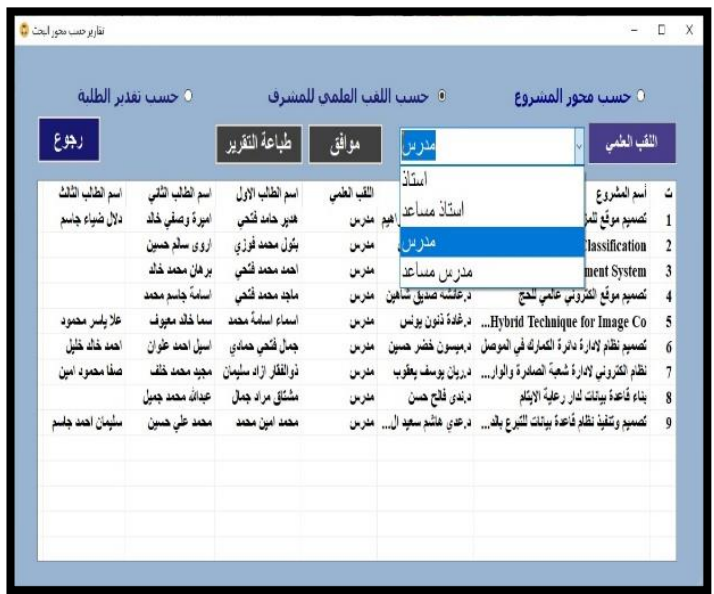

الثكل (21) يوضّح إعداد التقرير حسب اللقب العلمي

$$
\text { للمشرف }
$$

4- تقييم نتائج البحث:

بعد أن اختبر النظام فعلياً على معلومات حقيقية لقسم علوم الحاسوب عُمل استبيان للعاملين على النظام

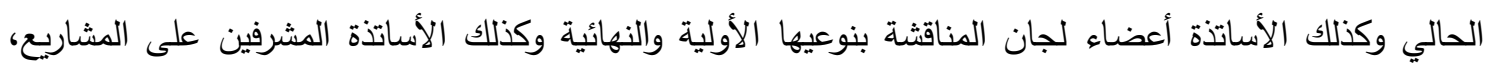


لوحظ ما يلي: 1) طريقة تسجيل الدخول للنظام سلسة وسهلة نالت ارتياح جميع المستخدمين للنظام. 2) تقييم الطلبة المشتركين في المشروع نفسه وبالوقت نفسه والواجهة نفسها لكل عضو في اللجنة منفرداً ومستقلاً أعطى لهُ ارتياحاً لأعضاء لجنة المناقشة. 3) سرية درجة تقييم المشروع التي يمنحها كل عضو في اللجنة جعل هنالك استقلالية في القرار بالنسبة لرؤوساء لجان المناقثة وأعضائها. 4) لوحظ فرق كبير في جهد العاملين على النظام وأوقاتهم وإمكانياتهم بطريقة فرز المشاريع وتوزيعها على الطلبة وعلى درجات المفاضلة وكذلك طريقة حفظ البيانات نال استحسان العاملين على النظام لسهولته وبساطته. 5) لوحظ عن طريق الاستبيان ارتياح كبير لاى اللجنة

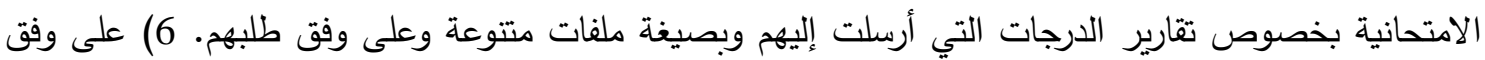
نتائج الاستبيات تبين ارتياح مستخدمي النظام حول الواجهات الخاصة بالنظام التي كانت منضمة وعلى وفق صنف المستخدم وسهولة استخدامها والألوان المنسقة وطريقة تسمية الأزرار على وفق المهام المطلوبة منها.

\section{5- 5 الاستنتاجات والاعمال المستقبلية:}

بعد إنجاز مراحل تطوير النظام نفذ النظام واختبر باستخدام أنموذج بيانات فعلية لمشاريع سابقة في قسم علوم الحاسوب/ كلية علوم الحاسوب والرياضيات/ جامعة الموصل، حقق من خلالها النظام المقترح جميع المتطلبات الوظيفية الموجودة في النظام التقليدي وبصورة سهلة وكفوءة خالية من الأخطاء، إن استخدام برامج التحليل مثل هن برنامج الـ UML، أسهم في إرساء أسس تطوير النظام وفق المفاهيم العلمية الصحيحة، كذلك انعكس استخدام اللغات والأدوات البرمجية الحديثة في تطوير واجهات النظام بصورة احترافية مما وفر المرونة والسهولة في التعامل مع واجهات النظام، فضلاً عن أن تطبيق النظام وفق مفهوم الأنظمة الموزعة ساعد على نحو كبير في جمع التقييمات من عدد من الممتحنين بصورة سريعة وإصدار التقارير النهائية بصورة آنية؛ إذ عملت طريقة تصميم

واجهات التقييم لكل ممتحن على زيادة سرية المعلومات واختصارها بمسؤول النظام والجهات الإدارية فقط. على الرغم من أنَّ النظام المقترح يلبي جميع المتطلبات الوظيفية وبصورة متكاملة لكن يبقى مجال التطوير مفتوحاً لإضافة مميزات جديدة، منها توسعة قاعدة البيانات لتكون شاملة؛ إذ يمكن تطوير النظام للعمل على تكوين قاعدة بيانات شاملة لجميع أقسام الكلية تربط لجان المشاريع مع اللجان الامتحانية وشعبة التسجيل. كذلك استخدام

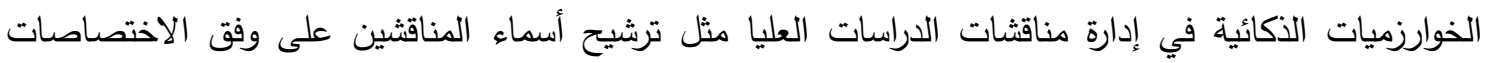
واحتساب المدة الدراسية وغيرها، كما يمكن إضافة خاصية متابعة المشاريع؛ إذ تُكن الجهات الإدارية من معرفة حالة كل مجموعة والمعوقات التي يواجهونها أثناء تطوير المشروع والعمل على تجازوها، وكذلك استخدام طرائق وتقانات تثفير حديثة لزيادة أمان النظام والحفاظ على خصوصية المعلومات وسلامتها. 


\section{المصادر}

علاء عبدالرزاق السالمي (2017). "تكنلوجيا المعلومات"، دار المناهج للنشر والتوزيع.

احمد علي السمان، مصطفى بسام علي (2012) "تصميم وتمثيل قواعد بيانات موزعة في الاعمال الطبية

باستخدام اوراكل"، رسالة ماجستير ، علوم الحاسوب، جامعة الموصل.

أيوب علي محمد سعيد (2010). "تصميم وتطبيق نظام موزع وقاعدة بيانات موزعة لأعمال دائرة

المرور". رسالة ماجستير، كلية علوم الحاسبات والرياضيات، جامعة الموصل.

عمار ظاهر ياسين (2009). "تصميم وتتفيذ قواعد بيانات موزعة لأعمال البنوك باستخدام الزمن

الحقيقي"، رسالة ماجستير غير منشورة، كلية علوم الحاسبات والرياضيات، جامعة الموصل.

Eötvös Loránd علي داؤود سلمان (2019). "مفاهيم عن الأنظمة المتوازية والمتزامنة والموزعة"،

.University

محمد عثمان عبدالرحمن أحمد، (2016). النظم الموزعة، جامعة الثيخ عبدالله البدري -بربر - السودان.

اباء عويشق، (2018). النظم الموزعة، منشورات الجامعة الافتراضية السورية.

احمد علي شمس الفلاح (2010). "إدارة مشاريع التخرج". جامعة السودان للعلوم والتكنلوجيا.

الخدمات الإلكترونية لإضافة مشروع التخرج، جامعة الملك عبد العزيز ، كلية الحاسبات وتقنية المعلومات.

إسراء آدم عبد الجليل، مهاد عثمان عبد الغفار، محمد فضل مودة، الحاج الامين بابكر (2016) "نظام

إدارة مشاريع التخرج"، جامعة السودان للعلوم والتكنولوجيا، كلية علوم الحاسوب وتقانة المعلومات.

اسماء محمد الفوارعة، عماد بدر ندية، بيان محمود مخامرة، رامي الدراويش (2017). "نظام إلكتروني

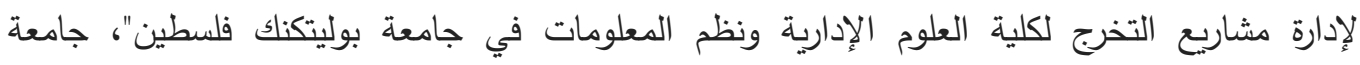

بوليتكنك فلسطين.

فاطمة محمود ابو صوان، سماح مشهور مسالمة، عبد الفتاح النجار (2013) "موقع الكتروني لإدارة

مشاريع التخرج في كلية العلوم الإدارية ونظم المعلومات"، جامعة بوليتكنك فلسطين.

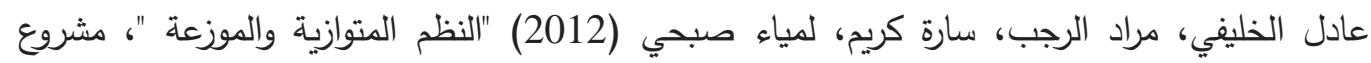

التخرج على الإنترنت، دراسة حالة جامعة الحصن، أبحاث حديثة في هندسة البرمجيات، 130-137.

بوردن كارين، ريبيكا جارلاند، واندرا بولك (2011) "مشروع التخرج NC " المدرسة العامة في ولاية

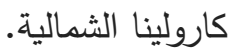

$$
\text { جيفري سباركس (2010)، مصمم المؤسسة، دليل المستخدم، أنظمة سباركس - البرمجة السابعة. }
$$

يريز بيسكر ورولف أولسون وكاليفي بيسي (2015)، مهنة مهند المؤسسة: دراسة تجريبية ، ECIME

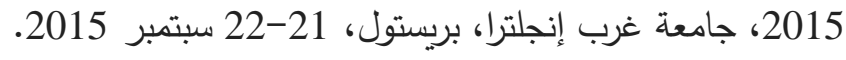

